\title{
Biogeochemical cycling of zinc and its isotopes in the Southern Ocean
}

\section{Journal Article}

Author(s):

Zhao, Ye; Vance, Derek; Abouchami, Wafa; De Baar, Hein J.W.

Publication date:

2014-01-15

Permanent link:

https://doi.org/10.3929/ethz-b-000071944

Rights / license:

Creative Commons Attribution-NonCommercial-NoDerivatives 4.0 International

Originally published in:

Geochimica et Cosmochimica Acta 125, https://doi.org/10.1016/j.gca.2013.07.045 
1

2

3

4

5

6

7

8

9

10

11

12

13

14

15

16

17

18

19

20

21

22

23

24

25

26

27

28

29

30

31 19 0

\section{Biogeochemical cycling of zinc and its isotopes in the Southern Ocean}

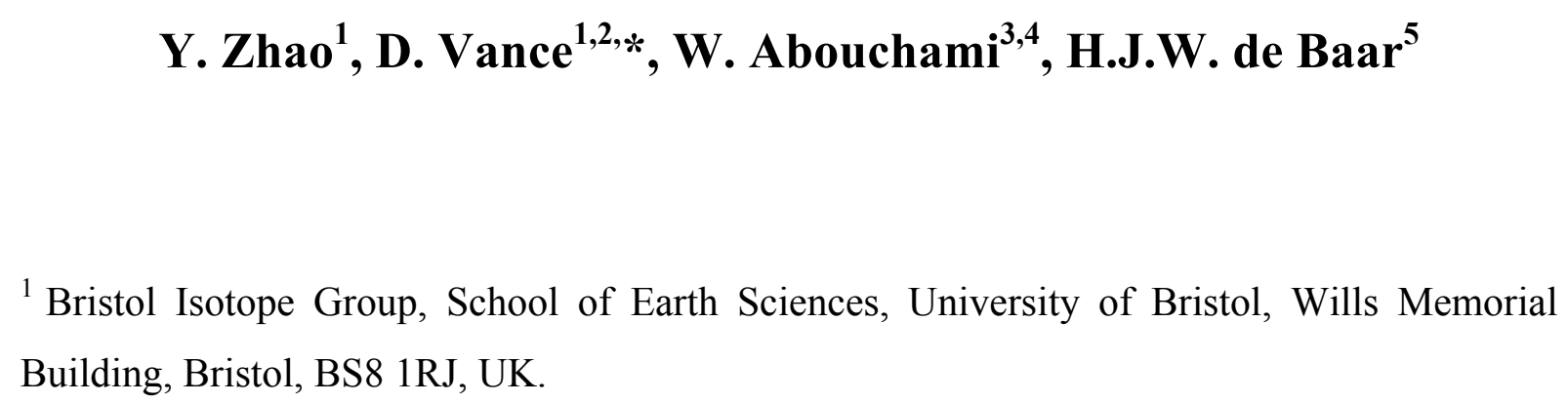

${ }^{1}$ Bristol Isotope Group, School of Earth Sciences, University of Bristol, Wills Memorial Building, Bristol, BS8 1RJ, UK.

${ }^{2}$ Institute of Geochemistry and Petrology, Department of Earth Sciences, ETH Zürich, NW D81.4, Clausiusstrasse 25, Zürich 8092, Switzerland.

${ }^{3}$ Max Planck Institute for Chemistry, P. O. Box 3060, 55020 Mainz, Germany.

${ }^{4}$ Institut für Mineralogie, WWU Münster, Corrensstraße 24, Münster, Germany.

${ }^{5}$ Royal Netherlands Institute for Sea Research, P.O. Box 59, 1790 AB Den Burg, The Netherlands.

*Corresponding author, tel: + 4144632 6881; fax: +41 44632 1376; e-mail:

derek.vance@erdw.ethz.ch.

11 figures.

3 tables

9 Electronic Supplementary Material

Keywords: GEOTRACES, Southern Ocean, biogeochemistry, zinc, isotopes 


\section{ABSTRACT}

We report $\mathrm{Zn}$ concentration and isotope data for seawater samples from the Atlantic sector of the Southern Ocean, collected during the IPY/GEOTRACES ANT-XXIV/III cruise along the Greenwich Zero Meridian. Data are reported for the full depth range of the water column at three stations, as well as a transect of surface samples, using a new analytical approach that is presented in detail here.

$\mathrm{Zn}$ concentrations increase with depth, though due to proximity to upwelling sites, surface concentrations are not as low as in some parts of the ocean such as further northward into the sub-Antarctic zone. For two depth profiles south of the Polar Front Zone, the physical stratification of the upper water column is reflected in sudden near-surface changes in $\mathrm{Zn}$ concentration with depth. In contrast, beneath $100-300 \mathrm{~m} \mathrm{Zn}$ concentrations barely change with depth. Zn isotopic data beneath $1000 \mathrm{~m}$, for the Southern Ocean data presented here as well as published data from the North Atlantic and North Pacific, are strikingly homogeneous, with an average $\delta^{66} \mathrm{Zn}=+0.53 \pm 0.14 \%$ ( $\left.2 \mathrm{SD}, 2 \mathrm{SE}=0.03, \mathrm{n}=21\right)$. The surface Southern Ocean is more variable, with $\delta^{66} \mathrm{Zn}$ ranging from $0.07-0.80 \%$. Between the two is a thin horizon at 40-80m which, in the Southern Ocean as well as the North Atlantic and North Pacific, is characterized by distinctly light isotopic signatures, with $\delta^{66} \mathrm{Zn}$ about $0.3 \%$ lower than surface waters.

Strong correlations between $\mathrm{Si}$ and $\mathrm{Zn}$ concentrations seen here and elsewhere, coupled to the lack of any systematic relationship between $\mathrm{Si}$ and $\mathrm{Zn}$ isotopes in the Southern Ocean, suggest that the removal of $\mathrm{Zn}$ associated with diatom opal involves little or no isotopic fractionation. Regeneration of this $\mathrm{Zn}$ also explains the homogeneous $\mathrm{Zn}$ isotopic composition of the global deep ocean so far sampled. However, the low $\mathrm{Zn}$ content of opal requires that deep ocean $\mathrm{Zn}$ does not directly come from the opal phase itself, but rather from associated 
56 organic material external to the diatom frustule during growth. Experimental data are 57 consistent with little or no fractionation during incorporation of $\mathrm{Zn}$ into this material. On the 58 other hand, the light zinc at $40-80 \mathrm{~m}$ is most consistent with the regeneration of an intra59 cellular pool that both culturing experiments and field data suggest will be isotopically light. 60 The data thus imply two processes by which $\mathrm{Zn}$ is taken up in the surface ocean, that these 61 pools have very different regeneration lengthscales, and that physical mixing of the oceans 62 cannot eradicate their isotopic signatures. Finally, the deep $\delta^{66} \mathrm{Zn}$ ocean value is significantly 63 higher than the current best estimate of the input to the oceans. The most obvious candidate 64 for the required light sink is the survival of some of the cellular $\mathrm{Zn}$ to be buried in sediment. 


\section{INTRODUCTION}

Zinc $(\mathrm{Zn})$ is involved in a number of biological processes in marine micro-organisms (see recent review by Sinoir et al., 2012), such as the important role as a cofactor in the enzyme carbonic anhydrase (Lippard and Berg, 1994) that promotes $\mathrm{CO}_{2}$ uptake in marine algae (Morel et al., 1994). Moreover, Zn displays nutrient-like depth profiles in the oceans (Bruland, 1980; Martin et al., 1989). For example, in the open Pacific, surface water concentrations of $\mathrm{Zn}$ are up to a factor of 250 times lower than those of deep waters, reflecting intense removal of $\mathrm{Zn}$ into phytoplankton at the surface and regeneration at depth (e.g. Lohan et al., 2002). In the surface ocean $\sim 98 \%$ of total dissolved $\mathrm{Zn}$ is chelated with strong Zn-binding organic ligands (Bruland, 1989; Donat and Bruland, 1990; Ellwood and van den Berg, 2000; Lohan et al., 2002; Bruland and Lohan, 2003), so that the concentration of bio-available $\mathrm{Zn}^{2+}$ (Sunda and Huntsman, 1992) is typically only $2-14 \mathrm{pM}$ in the photic zone of the open Pacific Ocean (Donat and Bruland, 1990). It has been suggested based on laboratory studies that, at this level, Zn could limit phytoplankton growth (Brand et al., 1983; Buitenhuis et al., 2003; Shaked et al., 2006; Sunda and Huntsman, 1992; Sunda and Huntsman, 1995; Sunda and Huntsman, 2005), though other evidence for such limitation is equivocal (e.g. Crawford et al., 2003; see recent review by Sinoir et al., 2012).

It is well known that photosynthetic uptake of carbon and the major nutrients (e.g. Altabet and Francois, 1994; Kroopnick, 1985; De La Rocha et al., 1998) involves a kinetic isotope fractionation such that, for example, phytoplankton preferentially take up ${ }^{12} \mathrm{C}$ over ${ }^{13} \mathrm{C}$, leading to enrichment in ${ }^{13} \mathrm{C}$ in surface waters. If the depletion of $\mathrm{Zn}$ in ocean waters is associated with a similar isotopic fractionation, then $\mathrm{Zn}$ isotopes could potentially be used to probe the mechanisms for $\mathrm{Zn}$ uptake and export from the surface ocean and, moreover, be used as a paleoceaonographic tracer in similar ways to foraminiferal $\delta^{13} \mathrm{C}$ (e.g. Andersen et al., 2011). Precise isotopic analysis of Zn (Maréchal et al., 1999) has only become possible 
91 since the development of multiple collector inductively coupled plasma mass spectrometry

92 (MC-ICPMS). Significant isotopic fractionation of $\mathrm{Zn}$ in marine and environmental systems

93 (roughly $2.5 \%$ total variation in $\delta^{66} \mathrm{Zn}$, see data compiled in Cloquet et al., 2006), resulting

94 from equilibrium and kinetic reactions during both biological and abiotic processes, have

95 since then been found in a number of studies, highlighting the potential of $\mathrm{Zn}$ stable isotopes as tracers (e.g. Maréchal et al., 1999, 2000; Weiss et al., 2005; Bermin et al., 2006).

97

98

In this paper we present, for the first time, depth profiles of $\mathrm{Zn}$ concentrations and isotopic compositions covering the entire water column, specifically from the Atlantic Sector of the Southern Ocean. The Southern Ocean is a key region for many global oceanic processes (Marinov et al., 2006), with water from all three oceans coalescing and mixing at depth. It is also an extensive High Nutrient-Low Chlorophyll (HNLC) region (Minas et al., 1986), where trace metals (e.g. Fe) are often cited as the limiting factor for primary productivity (e.g. Boyd and Ellwood, 2010). The aim of this contribution is therefore to assess the extent to which $\mathrm{Zn}$ isotope data can clarify the cycling of $\mathrm{Zn}$ in a region of the ocean where trace metals are biogeochemically important.

\section{OCEANOGRAPHIC SETTING}

The study region, at or near the Greenwich or Zero Meridian (Fig. 1), encompasses the eastward flowing Antarctic Circumpolar Current (ACC), which extends to its southern boundary (SB-ACC) from the Sub-Tropical Front (STF), and the Weddell Gyre, which extends from the SB-ACC to near the Antarctic continent. Within the ACC there are two more distinct fronts, the Sub-Antarctic Front (SAF) and the Antarctic Polar Front (APF). Within these latter frontal zones, which are narrow at any one time but meander through time, the ACC flows eastwards about 3-4 times more rapidly than outside them (Orsi et al. 1995). 
115 The positions of the fronts during the cruise is shown in Fig. 1. Between the fronts are three wide zones of slower eastward flow (Orsi et al. 1995), the Sub-Antarctic Zone (SAZ) between 117 the STF and SAF, the Polar Frontal Zone (PFZ) between the SAF and APF, and the Antarctic 118 Zone between the APF and SB-ACC. The Weddell Gyre comprises an eastward branch in the $119 \sim 58$ to $65^{\circ} \mathrm{S}$ region, and a westward return flow in the $\sim 65$ to $69^{\circ} \mathrm{S}$ region, the latter separated 120 from the Antarctic continent by the narrow, eastward flowing, Antarctic Coastal Current.

121 The Southern Ocean comprises all waters south of the STF. The APF is a boundary that is 122 very significant for this study, as follows. Briefly the hydrography of the Southern Ocean is 123 dominated by upwelling along the important frontal regions (Orsi et al., 1995, Fig. 1). 124 Upwelling of Circumpolar Deep Water (CDW) brings waters rich in major nutrients (nitrate, 125 phosphate and silicate) to the surface (Fig. 2). Part of these waters flows northwards where at 126 the APF two processes take place. Firstly some portion of the northward flowing water is 127 subducted at and beyond the APF to become Antarctic Intermediate Water (AAIW), relatively 128 rich in $\mathrm{N}, \mathrm{P}$ and $\mathrm{Si}$, flowing northwards at typically $\sim 1000 \mathrm{~m}$ depths far into the Atlantic, 129 Pacific and Indian Ocean basins. Another portion of the northward-flowing water remains at 130 the surface so that, at the APF, very intense summer blooms of large size classes of highly 131 silicified diatoms $\left(\mathrm{Si} / \mathrm{N}_{\text {diatom }}>3\right)$ utilize all available silicate (Queguiner et al., 1997). As a 132 result, north of the APF, dissolved silicate is depleted in surface waters, while nitrate and 133 phosphate decrease more gradually until final depletion at the Sub-Antarctic Front (SAF). 134 Another portion of the upwelled nutrient-rich waters flows southwards where eventually, due 135 to intense winter cooling and sea-ice formation in austral winter in the Weddell Sea, the water 136 sinks to form Weddell Sea Bottom Water (WSBW), which eventually flows northward as 137 nutrient-rich (N, P and Si) Antarctic Bottom Water (AABW). 
138 The general summer depletion of all three major nutrients in surface waters north of the SAF 139 implies that the northernmost Sub-Antarctic Zone (the SAZ, between the SAF and STF) of 140 the Southern Ocean can actually become macronutrient-depleted. In other words traveling 141 from north to south the surface waters of the Southern Ocean have three distinct regimes of 142 major nutrients: (i) the SAZ that in summer can become depleted in all three major nutrients $143 \mathrm{~N}, \mathrm{P}$ and $\mathrm{Si}$; (ii) the PFZ that is HNLC for two major nutrients $\mathrm{N}$ and $\mathrm{P}$, but depleted in $\mathrm{Si}$; 144 (iii) the Antarctic Ocean south of the APF, comprising the AAZ and Weddell Gyre, that is truly HNLC. In other words, the SAZ is in fact non-HNLC and limiting for all phytoplankton species, the PFZ is Si-limited for diatoms but has ample $\mathrm{N}$ and $\mathrm{P}$ for other phytoplankton 147 species, and only the Antarctic Ocean is fully HNLC for all three major nutrients i.e. there is 148 an adequate supply for growth of diatoms and all other phytoplankton such that, here, other 149 limitation(s) must exist. These distinctions are important here because in the other major oceans the vertical distribution of dissolved $\mathrm{Zn}$ has been shown to correlate strongly with dissolved silicate (e.g. Bruland, 1980). Therefore in this study of $\mathrm{Zn}$ and its isotopic composition, the APF is the distinct boundary between true HNLC conditions south of the 153 APF, as opposed to Si-limitation north of the APF. Accordingly, in terms of the major 154 nutrients and potential relationships with $\mathrm{Zn}$ and its isotopes, we focus here on Si rather than $155 \mathrm{~N}$ and $\mathrm{P}$.

156 Possible limiting factors for productivity in the HNLC zone include iron (Martin et al., 1990; 157 de Baar et al., 1990; Buma et al., 1991; de Baar et al., 1995), light (Mitchell et al., 1991; 158 Sunda and Huntsman, 1997; de Baar et al., 2005), and zooplankton grazing (Cullen, 1991). 159 Initial Fe fertilization experiments generally showed a much stronger response than those with 160 addition of other bio-essential trace metals, such as $\mathrm{Mn}, \mathrm{Co}, \mathrm{Cu}, \mathrm{Zn}$, or combinations thereof 161 (Buma et al., 1991; Scharek et al., 1997). Since then most studies of the role of trace metals in 162 the Southern Ocean (Boyd et al., 2000) have focused on iron (see recent review in Boyd and 
163 Ellwood 2010). More recently the covariance of dissolved Mn and phosphate in upper waters

164 of the same Greenwich meridian suggests some co-limitation of $\mathrm{Mn}$ and Fe at some times and 165 places in the Antarctic Ocean (Middag et al., 2011a). Also it has been suggested that sub166 optimal Zn concentrations in the Southern Ocean may influence Si and N uptake rates by 167 phytoplankton (Hassler et al., 2012). Previous water column work (Coale et al., 2005) has 168 revealed that $\mathrm{Zn}$ concentrations, like the major nutrients, are high near the upwelling zone in 169 the Antarctic Ocean and decline sharply northwards.

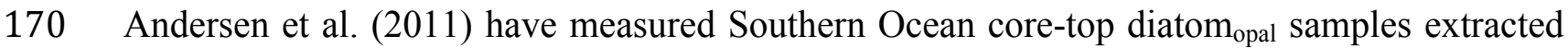

171 from marine sediments and reported systematic changes in $\delta^{66} \mathrm{Zn}$ associated with surface 172 water $\mathrm{Zn}$ concentrations. These systematic changes were found to be coupled to changes in $173 \mathrm{Zn} / \mathrm{Si}$ ratios of the diatom ${ }_{\text {opal }}$, which had been suggested previously (e.g. Ellwood and Hunter, 174 2000; Andersen et al., 2011) to reflect the concentrations of bio-available $\mathrm{Zn}$ in the ambient 175 surface seawater where the diatom ${ }_{\text {opal }}$ was formed. The $\delta^{66} \mathrm{Zn}$ and $\mathrm{Zn} / \mathrm{Si}$ of diatom opal, 176 therefore, have the potential to be used for investigating $\mathrm{Zn}$ cycling and primary productivity 177 in the past Southern Ocean.

\section{SAMPLES}

The seawater samples used in this study, were collected during cruise ANT-XXIV/3 (Feb181 April 2008) in the Atlantic sector of the Southern Ocean as part of the International 182 GEOTRACES program and a contribution to the International Polar Year (IPY). Seven 183 vertical profiles were taken, of which 3 were available for study here (Fig. 1, 2). These are at station 104 in the Si-depleted PFZ of the ACC, station 113 in the Si-N-P-rich HNLC AAZ region of the ACC, and station 163 in the Si-N-P-rich HNLC southernmost westward flowing

186 branch of the Weddell Gyre. In addition, large (20 litres) surface water samples (2-5m) were 
187 obtained along the Greenwich Zero Meridian from $47^{\circ} \mathrm{S}$ to $68^{\circ} \mathrm{S}$ (Fig. 1), some of which were 188 also available for study here. These are at station 105 in Si-depleted waters of the PFZ, 189 stations $109,111,114,117,120$ in the Si-N-P-rich HNLC AAZ region of the ACC, and 190 stations 123, 126, 129, 133, 136, 139 in the Si-N-P-rich HNLC of the northernmost eastward 191 flowing branch of the Weddell Gyre. Unfortunately, the surface samples that are likely to be 192 the most Zn-depleted, around and northward of the Sub-Antarctic Front, were exhausted by 193 other analyses and not available to us for study.

194 The TITAN trace metal clean rosette system from the Royal Netherlands Institute for Sea 195 Research (NIOZ) was used for seawater sampling (de Baar et al., 2008). The system consisted 196 of a titanium frame fitted with a standard Seabird CTD in a titanium housing, and 24 modified 19712 litre Teflon coated GO-FLO bottles deployed with a kevlar wire with internal signal cables 198 (de Baar et al., 2008). Sample bottles were tripped on the upcast using standard Seabird CTD 199 software. Upon recovery, the complete rosette was carefully moved into its dedicated NIOZ 200 Class-100 clean room container specially built for sub-sampling, where filtration and sub201 sampling were performed on the seawater samples using established protocols (Middag et al., 202 2011b). All seawater samples collected were acidified for storage to $\mathrm{pH}$ of around 2 using 203 Seastar $\mathrm{HCl}$. Bottles for sample collection were pre-cleaned with hot acid in the clean labs at 204 MPI. High density polyethylene (HDPE) containers of variable sizes for samples from 205 different water depths (20 litre for surface, 10 litre for intermediate, 5 litre and 1 litre for 206 deep) were subjected to a hot cleaning procedure consisting of successive treatment in 207 alkaline detergent and $6 \mathrm{M} \mathrm{HCl}$, followed by several ultra-pure MQ water rinses to remove 208 trace metal impurities. Sub-sampling for $\mathrm{Zn}$ isotopic analysis was done in the clean lab of 209 MPI. Bottles for sub-sampling were supplied by Bristol and pre-cleaned in $20 \% \mathrm{HCl}$ for 2 210 weeks, then rinsed 4 times with MQ before packing. 
211 Major nutrients were analyzed onboard by NIOZ using a Bran \& Luebbe Traacs 800 Auto212 analyser by standard methods described in Grasshoff et al. (1999). Samples for nutrient 213 measurement were obtained from a CTD rosette sampler (an ultraclean CTD) in a 214 polyethylene vial, stored in the dark at $4{ }^{\circ} \mathrm{C}$ and analyzed within 12 hours of sampling 215 (Fahrbach \& de Baar, 2010). A vertical section of measured silicate is plotted along the 216 Greenwich Zero Meridian in Fig. 2. As discussed above, the low Si concentration in SAZ and 217 PFZ in Fig. 2 is the result of the northward transport of upwelled Si-rich CDW water (south of $\left.21849^{\circ} \mathrm{S}\right)$, with the strong removal of silicate at the APF.

\section{METHODS}

221 In order to extract $\mathrm{Zn}$, present at nanomolar (nM) levels or lower, from up to several litres of seawater, an initial pre-concentration is required before purification for isotopic analysis.

223 Preliminary data from this laboratory (Bermin et al., 2006) used both Chelex-100 (Kingston et 224 al., 1978) and co-precipitation with $\mathrm{Mg}(\mathrm{OH})_{2}$ (Wu and Boyle, 1998). Extraction with Chelex225100 is adequate for high $\mathrm{Zn}$ concentration deep ocean samples, but for Zn-poor surface 226 samples the blank contribution from the Chelex column is unacceptably high (Bermin et al., 227 2006). Co-precipitation with $\mathrm{Mg}$ is achieved by adding ammonia to acidifed samples until the seawater's own inventory of dissolved $\mathrm{Mg}$ precipitates at $\mathrm{pH} \sim 10$ as $\mathrm{Mg}(\mathrm{OH})_{2}$, bringing

229 virtually all of the Zn with it. Again, this procedure performs adequately for Zn-rich deep 230 ocean samples where relatively small volumes $(<500 \mathrm{~mL})$ of seawater can be used. However, 231 for the large samples required to obtain enough $\mathrm{Zn}$ from depleted surface samples (in some 232 case $>2$ litres in this study), the $\mathrm{Mg}$ precipitate is so large that it causes difficulties during the 233 subsequent separation and purification of $\mathrm{Zn}$.

234 Here, a new pre-concentration approach has been used, involving the addition of a Zn-free 
235 aluminium solution to the seawater sample. The $\mathrm{pH}$ is then raised with ammonia, but in this 236 case only to about 8.5-9.0 so that $\mathrm{Al}(\mathrm{OH})_{3}$ precipitate is produced but no $\mathrm{Mg}(\mathrm{OH})_{2}$. Since the 237 amount of aluminium added can be controlled, subsequent handling of the precipitate during 238 the chromatographic purification of $\mathrm{Zn}$ is much easier. Since these are the first data we report 239 using this approach, we describe it in some detail in this section, including the tests we have 240 undertaken to establish its success. We also take the opportunity to compare the $\mathrm{Zn}$ 241 concentrations obtained here with those published previously for the same or similar locations 242 (Löscher, 1999; Croot et al., 2011).

243 All lab work was carried out under clean laboratory conditions in Class-100 laminar flow

244 clean hoods, using only Savillex (Minnetonka, MN, USA) PFA labware. All labware was 245 cleaned on the hotplate, firstly with $6 \mathrm{M} \mathrm{HCl}$, subsequently with $50 \% \mathrm{HNO}_{3}$ for two days, 246 then with $1 \%$ once distilled $\mathrm{HNO}_{3}$ for another day, rinsing thoroughly between each step and 247 at the end. 18.2 M $\Omega$ MQ water was obtained from a Millipore Q-Gard ${ }^{\circledR}$ B1 system. All acids 248 used were distilled twice.

\section{$249 \quad 4.1$ Pre-concentration by co-precipitation}

250 The initial step of co-precipitation was either done in large pre-cleaned Teflon beakers (up to 2511 litre), or in a clean 4 litre LDPE bottle (for samples $>1$ litre). Samples were weighed, and 252 Zn double spike and $1.2 \mathrm{ml} 10000 \mathrm{ppm} \mathrm{Al}$ standard solution were added. The commercial Al 253 solution was pre-cleaned of $\mathrm{Zn}$ on an anion column and subsequently re-dissolved in $1 \mathrm{M} \mathrm{HCl}$. 254 The ratio between sample and double spike $\mathrm{Zn}$ is ideally 1 (Bermin et al., 2006), but there is a 255 lot of leeway in this (see below). Beakers were left to equilibrate overnight, whereupon an 256 ultra-clean $\sim 11 \mathrm{M}$ Romil ammonia solution was added to reach a desired $\mathrm{pH}$. White precipitate 257 began to form and the beakers were left for a few more days for the precipitate to develop. 258 After this, as much supernatant as possible was poured off. Then the precipitate and 
remaining water was transferred to a smaller pre-cleaned Teflon beaker to settle again. The precipitate was then separated from the remaining supernatant by centrifugation. The centrifuged precipitate was washed with $\mathrm{pH}=10 \mathrm{MQ}$ (MQ to which a small amount of ammonia was added) and centrifuged again. The final "clean" precipitate was dissolved in 2 $\mathrm{ml} 7 \mathrm{M} \mathrm{HCl}$, dried down, taken up in $1 \mathrm{ml} 7 \mathrm{M} \mathrm{HCl}$ and dried down twice. The sample was finally dissolved in $1 \mathrm{ml}$ (or more, depending on the amount of precipitate obtained) $1 \mathrm{M} \mathrm{HCl}$, before passing through the anion exchange column for further purification.

The aluminium solution, despite being pre-cleaned on a column, was a significant contributor to the total blank. In addition, co-precipitation at too high a $\mathrm{pH}$ causes precipitation of unwanted $\mathrm{Mg}$ hydroxide from seawater in addition to aluminium hydroxide. Tests were therefore conducted to ascertain the smallest amount of Al solution that could be used, as well as the minimum $\mathrm{pH}$ for co-precipitation, while maintaining high $\mathrm{Zn}$ yields. Because of the double spike approach, high Zn yields are not essential for accuracy, but they are desirable to maximize the final analyte signal during mass spectrometry. Based upon the results of these tests (see Electronic Supplementary Material (ESM), Fig. 1), it was decided to add $1.2 \mathrm{ml}$ of Al solution $(12 \mathrm{mg})$ and to raise the $\mathrm{pH}$ to $8.5-8.8$ during co-precipitation. In both cases this procedure produced yields in excess of 90\% (Tables 1-3) for sample sizes $\leq 1$ litre, and greater than $70 \%$ for sample sizes $>1$ litre, where quantitative recovery of the precipitate from 4 litre bottles was difficult.

\subsection{Column Chemistry}

The column procedure described by Maréchal et al. (1999), modified by Archer and Vance (2004), has been adopted, with some further minor modifications. Primarily, $1 \mathrm{M} \mathrm{HCl}$ has been used instead of $7 \mathrm{M} \mathrm{HCl}$ to dissolve precipitate and eliminate seawater matrix. There were two reasons for this: 1) $1 \mathrm{M} \mathrm{HCl}$ would contribute less blank than $7 \mathrm{M} \mathrm{HCl}$; 2) it was 
easier to dissolve $\mathrm{Al}(\mathrm{OH})_{3}$ in $1 \mathrm{M} \mathrm{HCl}$ than in $7 \mathrm{M} \mathrm{HCl}$. Samples were loaded to the column

284 in $1 \mathrm{ml}$ (or $2 \mathrm{ml}$, depending on the amount of precipitate to be dissolved) $1 \mathrm{M} \mathrm{HCl}$. Most 285 metals were washed off in $12 \mathrm{ml} 1 \mathrm{M} \mathrm{HCl}$ before $\mathrm{Zn}$ was collected in $4 \mathrm{ml} 2 \% \mathrm{HNO}_{3}$. A 286 column calibration was performed with Zn JMC standard and the result suggested that no $\mathrm{Zn}$ 287 was eluted until $2 \% \mathrm{HNO}_{3}$ was put through the column. The measured column blank of this 288 procedure was $0.2 \mathrm{ng}$ for $\mathrm{Zn}$.

\subsection{Procedural Blanks}

290 Quantifying the blank for a co-precipitation procedure is difficult because in order to re291 produce the entire procedure a seawater sample that contains a finite amount of Zn must be 292 used, so that all measured blanks will be maxima. Ultrapure water can be used as the 293 "seawater" sample but, again, the large quantities of this that must be used to simulate the 294 measured seawater sample will contain finite amounts of $\mathrm{Zn}$. Here we quantified the 295 maximum blank by extracting $\mathrm{Zn}$ from different volumes of MQ water, adding the same amount of Al solution as for samples to each, as well as an amount of ammonia appropriate for an acidified 1 litre seawater sample (the ammonia blank was insignificant relative to other sources at $7 \mathrm{pg} / \mathrm{ml}$ ). Duplicate sets of results for these MQ "samples" (Figure 2 in the ESM), suggest a procedural blank for real samples of $\sim 2 \mathrm{ng}$. A further constraint derives from analyses performed on extremely Zn-depleted surface samples from the Equatorial Atlantic, samples that turned out to contain as little as $0.01 \mathrm{nM} \mathrm{Zn}$, as determined by isotope dilution. For these 4 litre samples this implies a total amount of $\mathrm{Zn}$ found of about $2.5 \mathrm{ng}$. reveal it to be substantially lower. Sample volumes analysed here ranged from $0.1-2.2 \mathrm{~L}$, 305 yielding total amounts of $\mathrm{Zn}$ analyzed of $34-219 \mathrm{ng}$. With the above absolute maximum procedural blank of $3 \mathrm{ng}$, the $\mathrm{Zn}$ blank contribution to the smallest sample analyzed was less 
307 than 9\%. Previous measurements of the isotopic composition of (larger) blanks in this

308 laboratory gave $\delta^{66} \mathrm{Zn}=0.17 \pm 0.18 \%$ (Bermin et al., 2006; $\delta^{66} \mathrm{Zn}_{\text {JMC-Lyons }}=$ $309\left[\left({ }^{66} \mathrm{Zn} /{ }^{64} \mathrm{Zn}_{\text {sample }}{ }^{66} \mathrm{Zn} /{ }^{64} \mathrm{Zn}_{\text {JMC-Lyons }}\right)-1\right] \mathrm{x} 1000$, where JMC-Lyons refers to the Johnson Matthey 310 zinc standard JMC batch 3-0749, obtained from the lab of Francis Albarède; Maréchal et al., 311 1999). All samples measured here were corrected for the contribution of a 3 ng blank with an 312 isotopic composition of $+0.2 \%$, but the size of these corrections is insignificant for all 313 measured isotopic compositions compared to other sources of analytical uncertainty. In other 314 words, if the blank contribution was really close to zero, the data reported in the paper would 315 not change by more than about $0.03 \%$.

\section{$316 \quad 4.4$ Mass Spectrometry}

317 Isotopic analysis of Zn was performed on a Thermo Finnigan Neptune MC-ICPMS at Bristol 318 at low mass resolution. Samples were introduced into the mass spectrometer in $2 \%(\mathrm{v} / \mathrm{v})$ nitric 319 acid via an Aridus desolvating nebuliser system (Cetac, Omaha, NE, USA) and desolvating 320 spray chamber. The spray chamber was held at $105^{\circ} \mathrm{C}$ and the desolvator at $160^{\circ} \mathrm{C}$. Typical 321 Ar sweep gas settings were $4.25-4.75 \mathrm{~L} / \mathrm{min}$ with little day-to-day variation in the sweep gas 322 required to obtain the optimum $\mathrm{Zn}$ signal. No $\mathrm{N}_{2}$ was used as $\mathrm{ArN}_{2}$ would result in 323 interference on ${ }^{68} \mathrm{Zn}$. All stable isotopes of $\mathrm{Zn}$, as well as ${ }^{62} \mathrm{Ni},{ }^{63} \mathrm{Cu},{ }^{65} \mathrm{Cu}$ were collected 324 simultaneously in static mode using a multiple Faraday collector array. Data collection 325 consisted of 30x4s integrations and each measurement was preceded by a blank measurement $326\left(15 \times 4\right.$ s integrations) of the $2 \% \mathrm{HNO}_{3}$ used to make the analyte solutions and followed by a 327 wash or two in clean $2 \% \mathrm{HNO}_{3}$. The blank signal was subtracted from the sample signal and 328 normally amounted to no more than $0.02 \%$ of total analyte 64 ion beam.

329 All Zn isotopic data are reported relative to the Johnson Matthey Zinc standard JMC 3-0749, 330 obtained from the lab of Francis Albarède (Maréchal et al., 1999). The standard delta per mil 
notation is used and is defined as:

332

$$
\delta^{66} Z n=\left[\frac{\left({ }^{66} \mathrm{Zn} /{ }^{64} \mathrm{Zn}\right)_{\text {sample }}}{\left({ }^{66} \mathrm{Zn} /{ }^{64} \mathrm{Zn}\right)_{J M C}}-1\right] \times 1000
$$

333 Mass discrimination artefacts, that may be introduced at any stage in the chemical and mass

334 spectrometric procedure, were corrected using the double spike method as detailed in Bermin 335 et al. (2006). All uncertainties cited are 2SE of 304 second integrations propagated through 336 the full double spike reduction procedure unless specified. To test the robustness of the 337 double spike approach, JMC standard and double spike were mixed at various ratios and analyzed during every analytical session (see Fig. 3 in ESM for data).

\subsection{Tests on real seawater samples}

$340 \mathrm{Zn}$ isotopic data for samples from the GEOTRACES IC1 intercalibration project (BATS 341 station, $31^{\circ} 40^{\prime} \mathrm{N} 64^{\circ} 10^{\prime} \mathrm{W}$ ) have already been reported by this laboratory (Boyle et al. 2012). 342 No other $\mathrm{Zn}$ data were reported for these samples so that we cannot demonstrate inter343 laboratory consistency at this stage. However, the duplicates analysed by us and reported in 344 Boyle et al. (2012) are all consistent with each other. Furthermore, analyses of deep ocean 345 samples by S. John and T. Conway (pers. comm. September 2012) are yielding the same 346 results as we obtain here and in Boyle et al. (2012). There are a number of other laboratories 347 now pursuing $\mathrm{Zn}$ isotopic measurement of seawater so that we hope that this situation 348 improves soon. With this in mind Table 1 reports data obtained here for other samples from recent intercalibration efforts.

350 Though no isotopic data have been reported yet for these samples from other laboratories, the

351 concentrations obtained here are consistent with those measured elsewhere with completely 352 independent approaches. Thus the consensus values for $\mathrm{Zn}$ in SAFe D1 and D2 are 7.1 \pm 0.6 
353 and $7.2 \pm 0.5 \mathrm{nmol} \mathrm{kg}^{-1}$ while that for the SAFe surface sample is also identical to those

354 obtained

here $\quad$ at $\quad 0.064 \pm 0.019$

nmol

$\mathrm{kg}^{-1}$

355

(http://es.ucsc.edu/ kbruland/GeotracesSaFe/kwbGeotracesSaFe.html). The Bruland

356 laboratory at Santa Cruz has measured $1.42 \mathrm{nmol} \mathrm{kg}^{-1}$ for $\mathrm{Zn}$ in the Santa Barbara sample,

357 whereas we obtain 1.35 and $1.37 \mathrm{nmol} \mathrm{kg}^{-1}$ for two duplicate aliquots from two different 358 bottles.

\section{$359 \quad 4.6$ Standard-addition tests}

360 Another test of our procedure involves the addition of standard to seawater samples from

361 which $\mathrm{Zn}$ has been removed, to seawater samples with very small natural Zn concentrations, 362 and to MQ water, all followed by pre-concentration, column purification and mass 363 spectrometric analysis. Fig. 3 shows results obtained for addition of variable amounts of JMC 364 standard to seawater samples from which $\mathrm{Zn}$ had been removed (supernatant poured off from 365 a previous $\mathrm{Al}$ co-precipitation, retained and treated as a new "sample") and MQ. The result 366 for the seawater samples was $\delta^{66} \mathrm{Zn}=+0.08 \pm 0.03 \%(\mathrm{n}=12)$, and for MQ $\delta^{66} \mathrm{Zn}=-0.01 \pm$ $3670.02 \%(\mathrm{n}=8)$. Although the value for the seawater supernatant samples was close to zero, the 368 data indicate that a small amount of seawater $\mathrm{Zn}$ was left in the supernatant after co369 precipitation, resulting in the slightly elevated $\delta^{66} \mathrm{Zn}$. Evidence for this came from the 370 comparison of seawater supernatant samples with different amounts of JMC standard added.

371 For those with only $30 \mathrm{ng}$ of standard $\mathrm{Zn}$ added, the $\delta^{66} \mathrm{Zn}$ was more elevated from the 372 expected $0 \%$ (and also closer to the seawater $\delta^{66} \mathrm{Zn}$ ) than those to which $200 \mathrm{ng}$ of standard 373 Zn was added, due to a larger relative contribution of the residual seawater $\mathrm{Zn}$. A sample 374 calculation illustrates how this is possible. For example, for $30 \mathrm{ng}$ of standard $\mathrm{Zn}$ added, the 375 typical shift away from $0 \%$ at the limits of uncertainty is about $0.1 \%$ owards the original seawater sample value of $+0.46 \%$. Thus the shift is of the order of $20 \%$ of the total difference 
between the predicted $0 \%$ and the original seawater sample. This would require an amount of residual seawater $\mathrm{Zn}$ of $8 \mathrm{ng}$. If the yield from the original co-precipitation is $90-95 \%$, and given an original amount of $\mathrm{Zn}$ in the seawater sample of around 100ng for these samples, then a residual amount of seawater $\mathrm{Zn}$ of around $5-10 \mathrm{ng}$ is plausible. Data for the MQ samples, which had negligible amounts of $\mathrm{Zn}$ originally, all fell within the error of the expected $0 \%$ (Fig. 3).

Another test was performed by adding different amounts of standard JMC $\mathrm{Zn}$ to a set of 4 litre samples obtained from the surface Equatorial Atlantic, which through previous analysis by isotope dilution had been found to contain only $0.01-0.03 \mathrm{nmol} \mathrm{kg}^{-1}$ sample $\mathrm{Zn}$. The data are illustrated in Figure 4. The good fit of the data to a straight line might be taken to indicate simple mixing between standard $\mathrm{Zn}\left(\delta^{66} \mathrm{Zn}=0\right.$, low $\left.1 / \mathrm{Zn}\right)$ and sample $\mathrm{Zn}$.

\subsection{Intercomparison of $\mathrm{Zn}$ concentrations with previous data from the Southern Ocean}

Seawater samples from locations close to those analysed in this paper have been the subject of two other studies for $\mathrm{Zn}$ concentrations (Löscher, 1999; Croot et al., 2011). Direct intercomparison between these studies and ours is made difficult by the fact that the previous studies are not often from precisely the same location, depths etc. Figure 5 shows a depth profile from our Station PS71-113-2 along with data from exactly the same location for samples collected on the same cruise with the same sampling equipment and filtration (Croot et al., 2011), and data from a composite depth profile made up of samples from other nearby sites in the Southern ACC collected in 1992 (Löscher, 1999). The latter dataset is from a time when contamination control during sample collection was a lot more difficult than now, and has some outliers, but it is also clear that the agreement between these data and ours at depths $\geq 1000 \mathrm{~m}$ is essentially perfect. The data from Croot et al. (2011), on the other hand, are about $25-50 \%$ lower than both our data, and the Löscher (1999) data beneath $1000 \mathrm{~m}$ where a 
401 meaningful comparison can be made. The Croot et al. (2011) data were obtained using 402 simultaneous dithiocarbamate-freon extraction followed by graphite furnace atomic 403 absorption spectroscopy. Since the publication of the Croot et al. (2011) data, it has become 404 apparent that this approach, when performed on samples that have been acidified with $\mathrm{HCl}$, 405 yields $\mathrm{Cd}$ concentrations that are up to about 50\% lower than by isotope dilution (O. Baars 406 and W. Abouchami, unpublished data). It seems likely that this problem applies also to the 407 Croot et al. (2011) Zn data. It may be related to incomplete stripping of the metals from 408 organic complexes during the pre-concentration step. The problem is particularly apparent in 409 samples that had been acidified with $\mathrm{HCl}$ and analysed shortly after acidification, while it can 410 be eliminated for samples that are acidified using oxidizing acids like $\mathrm{HNO}_{3}$ (P.L. Croot, pers. 411 comm.).

\section{RESULTS}

\section{$414 \quad 5.1$ Three vertical profiles along Greenwich Zero Meridian}

415 Data for the three vertical profiles PS71-104-2, PS71-113-2, PS71-163-1 (Fig. 1) analysed in this study for dissolved $\mathrm{Zn}$ concentrations and isotopic compositions are presented in Table 2.

417 The data are shown as depth profiles, with other key oceanographic parameters, in Fig. 6-8.

418 The water column at the most southerly station, PS71-163-1 (Fig. 6), in the Weddell Gyre, is 419 extremely stratified at the surface, with temperature and salinity increasing quickly from 420 surface minima of $-0.8^{\circ} \mathrm{C}$ and 34 , to about $0.9^{\circ} \mathrm{C}$ and 34.7 at the AASW (Antarctic surface 421 water) - CIW (Central Intermediate Water) boundary at 200m. This stratification must be 422 driven by the low surface salinity, given the sharp $1.7^{\circ} \mathrm{C}$ decrease in temperature in the 423 surface layer. The AASW-CIW boundary also corresponds to an $\mathrm{O}_{2}$ minimum. Si is relatively 424 high at the surface $(60 \mu \mathrm{mol} / \mathrm{kg})$ and also increases sharply with depth, but the AASW-CIW 
425 boundary is not as sharp as for the physical parameters or $\mathrm{O}_{2}$. Though there is an inflexion in

426 the Si depth profile at this depth, concentrations continue to increase relatively smoothly

427 through it.

428 The $\mathrm{Zn}$ concentration profile looks more like salinity than $\mathrm{Si}$. Zn concentrations are not 429 particularly low at the surface $(2.5 \mathrm{nM})$, and increase quickly to about $7 \mathrm{nM}$ at $74 \mathrm{~m}$. Beneath 430 this boundary, salinity, oxygen and $\mathrm{Zn}$ are very homogeneous with depth, with $\mathrm{Zn}$ 431 concentrations between 7.1 and $7.8 \mathrm{nM}$. There is a slight maximum $(7.8 \mathrm{nM})$ at $1000-$ $4321500 \mathrm{~m}$, close to the CIW-WSDW (Weddell Sea Deep Water) boundary. Si concentrations, by 433 contrast, continue to increase beneath the AASW-CIW boundary and only reach their 434 maximum in the bottom-most sample measured. The $\delta^{66} \mathrm{Zn}$ profile shows a maximum of $435+0.67 \%$ at the surface, in contrast to quite an extreme minimum of $+0.27 \%$ within AASW at $43645 \mathrm{~m}$. Beneath this, from $170-4000 \mathrm{~m}, \delta^{66} \mathrm{Zn}$ is extremely homogeneous at $+0.53 \pm 0.10 \%$ 437 (2sd). There is a very slight minimum $(+0.44 \%$ to $+0.49 \%)$ at the AASW-CIW boundary, 438 and a very slight, broad, maximum $(+0.64 \%$ at $1000-2000 \mathrm{~m}$, decreasing to $+0.53 \%$ at $4394000 \mathrm{~m})$, but these features are barely analytically significant. The bottom-most sample shows $440 \quad$ very anomalous $\delta^{66} \mathrm{Zn}$ at $+0.97 \%$.

441 Station PS71-113-2 (Fig. 7) is within the ACC, in the Antarctic Zone to the south of the Polar 442 Front. The major physical oceanographic difference between this station and PS71-163-1 is 443 slightly less extreme stratification, though it is still significant. The upper $100 \mathrm{~m}$ of the water 444 column has the low salinity that is characteristic of AASW, and is also characterized by 445 homogeneously high dissolved $\mathrm{O}_{2}$ and moderately low, $\mathrm{Si}$ (at $35 \mu \mathrm{mol} \mathrm{kg}^{-1}$ ). Potential 446 temperature is more variable at $1.2-1.4^{\circ} \mathrm{C}$. The core of UCDW (Upper Circumpolar Deep 447 Water $)$ beneath AASW is characterized by a temperature maximum $\left(\sim 1.6^{\circ} \mathrm{C}\right.$ at $\left.400 \mathrm{~m}\right)$ and a 448 slight $\mathrm{O}_{2}$ minimum (185 $\mu \mathrm{mol} \mathrm{kg}{ }^{-1}$ at $\left.400 \mathrm{~m}\right)$. Salinity shows a very slight maximum in 
449 UCDW. Beneath the core of UCDW, salinity and $\mathrm{O}_{2}$ remain relatively constant to the bottom.

450 Si in contrast increases sharply at first in UCDW, down to the core of UCDW, and then more 451 slowly but monotonically to the bottom.

452 The pattern of the Zn concentration profile, as with Station PS71-163-1, looks more like 453 salinity and inverse $\mathrm{O}_{2}$ than $\mathrm{Si}$. AASW at $0-100 \mathrm{~m}$ is characterized by the lowest $\mathrm{Zn}$ 454 concentrations, but still relatively high for surface water, at $2.6-3.1 \mathrm{nM}$. There is then a step 455 change into UCDW, resembling the sharp increase in salinity and drop in $\mathrm{O}_{2}$. UCDW $\mathrm{Zn}$ 456 concentrations are homogeneously high at around $6.3-6.6 \mathrm{nM}$. In LCDW (Lower 457 Circumpolar Deep Water), Zn concentrations increase slightly to $6.8-7.1 \mathrm{nM}$, but relative to $458 \mathrm{Si}$, for example, are relatively homogeneous from $100 \mathrm{~m}$ to the bottom of the water column.

459 The $\delta^{66} \mathrm{Zn}$ profile at PS71-113-2 exhibits a clearer structure than that at PS71-163-1. As with 460 PS71-163-1, the $\delta^{66} \mathrm{Zn}$ profile at PS71-113-2 has a pronounced surface maximum $(+0.8 \%$ ), 461 and again there is a sharp drop in the sub-surface, to +0.47 to $+0.54 \%$ at $74-101 \mathrm{~m}$, still 462 within AASW. Note that no sample has been measured at 40-50m in this profile (c.f. more 463 pronounced minima at $40-50 \mathrm{~m}$ at both stations 163-1 and 104-2; Table 2). Uppermost 464 LCDW has a $\delta^{66} \mathrm{Zn}$ value of $+0.70 \%$ at $1000 \mathrm{~m}$. Between AASW and uppermost LCDW, 465 UCDW appears to have a lower $\delta^{66} \mathrm{Zn}$, at $+0.39 \%$ o to $+0.48 \%$, a minimum that is just about 466 analytically significant relative to the values immediately above and below. Below 1000m, 467 and for the remainder of LCDW down to the bottom at $2351 \mathrm{~m}$, the $\delta^{66} \mathrm{Zn}$ value decreases 468 gradually and monotonically, from the high of $+0.70 \%$ at $1000 \mathrm{~m}$ to $+0.43 \%$ at the bottom. 469 As noted above, $\mathrm{Zn}$ concentrations change very little through this isotopic structure in the 470 lower water column beneath AASW.

471 Station PS71-104-2 (Fig. 8) is also within the ACC, in the low-Si PFZ, between the APF and 472 the SAF. The upper water column at this station is significantly less stratified than the other 
473 two. This station is in the Polar Frontal Zone formation region of AAIW, and surface salinity

474 is marked by the minimum (33.73) that is characteristic of that water mass. Salinity then 475 increases to a slight maximum (34.78) at 2000m, in the upper levels of NADW (North 476 Atlantic Deep Water, see Fig. 3 of Middag et al., 2011a). The core of UCDW is characterized 477 by the same minimum in dissolved oxygen seen at Station PS71-113-2. Temperature 478 decreases monotonically downward from a surface maximum of $6.5^{\circ} \mathrm{C}$, though with inflection 479 points near the boundaries of the main water masses. Surface Si concentrations are much 480 lower than the other two stations - at $\sim 1.9 \mu \mathrm{M}$ here in contrast to 63 and $35 \mu \mathrm{M}$ at the other 481 two stations. Si increases monotonically downward, though again with inflection points at the 482 boundaries of the water masses, notably at the UCDW-NADW boundary, above which Si is 483 relatively constant with depth but below which there is a renewed increase.

484 The $\mathrm{Zn}$ concentration profile, in contrast to those at the other two stations studied, looks much 485 more like Si than salinity. Surface Zn concentration is much lower at this station, at $0.32 \mathrm{nM}-$ 486 a feature that mirrors the $\mathrm{Si}$ contrast between the three stations. $\mathrm{Zn}$ concentrations then 487 increase steeply through AAIW to reach a maximum of $\sim 5.35 \mathrm{nM}$ at $1000-1500 \mathrm{~m}$ in the 488 core of UCDW. This maximum occurs at the same depth as the homogeneous $\mathrm{Si}$ 489 concentrations above the UCDW-NADW boundary. Zn concentrations then undergo a 490 renewed increase through NADW and into LCDW, reaching $8.04 \mathrm{nM}$ at $4006 \mathrm{~m}$. The bottom491 most point has distinctly lower $\mathrm{Zn}$ concentration at $7.03 \mathrm{nM}$.

492 As with the other two profiles $\delta^{66} \mathrm{Zn}$ shows a clear change from a higher value right at the 493 surface $(+0.47 \%)$ to a minimum at $50 \mathrm{~m}(+0.25 \%)$. Through the remainder of AAIW and $494 \mathrm{UCDW}, \delta^{66} \mathrm{Zn}$ returns to homogeneously heavier values (at $+0.44 \pm 0.06 \%$ at $100-2000 \mathrm{~m}$ ), 495 consistent with the values for UCDW seen at Station PS71-113-2 $(+0.39 \%$ o to $+0.48 \%)$. 496 NADW and LCDW appear to be characterized by slightly heavier values, with two 
497

498

499

500

501

502

503

504

505

506

507

508

509

510

511

512

513

514

515

measurements at $+0.60 \%$ and $0.61 \%$. Again, this is consistent with the heavier values seen in LCDW - up to $+0.70 \%$ - relative to UCDW at Station PS71-113-2. A slightly lower $\delta^{66} \mathrm{Zn}$ is found in the bottom-most sample than directly above, paired with the distinctly lower $\mathrm{Zn}$ concentration in this sample relative to the measurement directly above.

\subsection{Surface transect along Greenwich Zero Meridian}

In addition to the above depth profiles, samples from 11 surface transect stations PS105, PS109, PS114, PS117, PS120, PS123, PS126, PS129, PS133, PS136, PS139 were also analysed for dissolved $\mathrm{Zn}$ concentrations and isotopic compositions. Data are presented in Table 3. The $\mathrm{Zn}$ data, with other key oceanographic parameters, are plotted against latitude in Fig. 9.

Note that though the $\mathrm{Zn}$ concentration reproduces across duplicate analyses of two separate aliquots from the same 20 litre MPI container, the data for Station PS111 (52.17 $\left.{ }^{\circ} \mathrm{S}\right)$ are highly anomalous. We suspect that the original 20 litre MPI bottle must have been contaminated before or during original sampling, and these data are not plotted, nor considered further in the results and discussion sections below. Relatively smooth transitions between the other samples across the latitudinal transect suggest no such problems.

The surface transect sampling stations covered, from north to south, the PFZ, the Antarctic Zone (AAZ) of the ACC and the northern end of the Weddell Gyre. The highest Si values are in the Weddell Gyre and the region of strong upwelling in the AAZ of the Southern ACC (c.f. Fig. 2). The peak in surface $\mathrm{Zn}$ concentrations also occurs here, but is sharper and centered on $58^{\circ} \mathrm{S}$, near the boundary between the Weddell Gyre and the Antarctic Circumpolar Current. In fact, as with the depth profiles, the pattern of Zn concentrations in the southern regions of the surface transect most closely matches salinity. Both salinity and $\mathrm{Zn}$ have a sharp peak near the boundary between the Weddell Gyre and the Antarctic Circumpolar Current, and more rapidly 
521 declining values north of this as far as about $53^{\circ} \mathrm{S}$. Thereafter, further north, the pattern in $\mathrm{Zn}$ 522 concentrations begin to look more like that of Si.

$523 \delta^{66} \mathrm{Zn}$ is relatively constant at $+0.45 \%$ to $+0.6 \%$ across the Weddell Gyre and into the

524 southern $\mathrm{ACC}$ as far as about $53^{\circ} \mathrm{S}$ (Fig. 9). The only datum that is significantly different 525 along the entire transect is at $48^{\circ} \mathrm{S}(+0.10 \%)$.

\section{DISCUSSION}

\subsection{Controls on $\mathrm{Zn}$ isotope systematics in surface waters}

Overall, the $\mathrm{Zn}$ isotope data reported here display a total variation in $\delta^{66} \mathrm{Zn}$ of about $0.9 \%$, representing about $40 \%$ of the total variation yet reported for $\mathrm{Zn}$ isotopes on Earth (see

531 compilation in Cloquet et al., 2006). However, perhaps the most striking aspect of the 532 Southern Ocean depth profiles is their relative homogeneity. Thus, apart from one outlier, the 533 datum for the deepest sample at location PS-71-163-1 (at $+0.96 \%$ ), the variation in the entire 534 dataset beneath $50 \mathrm{~m}$ is only at about the 4 sigma level (mean and $2 \mathrm{SD}=0.51 \pm 0.15 \%$ ). There 535 is more variation above $50 \mathrm{~m}$, with $\delta^{66} \mathrm{Zn}$ values as high as $+0.8 \%$ and as low as $0.07 \%$.

$536 \mathrm{Zn}$ depletion in the surface ocean is generally attributed to biological uptake, and enrichments at depth as due to return of $\mathrm{Zn}$ to the dissolved pool from particulate material that is

538 biologically-packaged in the photic zone (e.g. Bruland and Lohan, 2003 and Sinoir et al., 539 2012). If biological uptake of $\mathrm{Zn}$ in the surface ocean is associated with even a small isotope 540 fractionation there should be a clear impact on the isotopic composition of the small residual 541 surface pool. Though upwelling of nutrient-rich waters means that surface Zn concentrations 542 are not nearly as low in our study area as in many parts of the ocean (e.g. Bruland, 1980; 543 Lohan et al., 2002; Boyle et al., 2012), it is still the case that $\mathrm{Zn}$ concentrations at 5-15m are 544 up to 20 times lower than those of the deep Southern Ocean. Even if the kinetic fractionation 
545 associated with cellular uptake of $\mathrm{Zn}$ is as small as $+0.2 \%$ o $\left(\delta^{66} \mathrm{Zn}_{\text {dissolved }}-\delta^{66} \mathrm{Zn}_{\text {cell }}\right)$, a residual 546 dissolved pool of 5\% should be $0.6 \%$ heavier than the $\mathrm{Zn}$ upwelled from the deep ocean, 547 assuming Rayleigh fractionation in a closed system. The implied heavy dissolved phase $\delta^{66} \mathrm{Zn}$ 548 are not seen in the surface waters analysed here.

549 One obvious potential reason for the lack of an imprint on isotopic compositions of strong 550 apparent vertical $\mathrm{Zn}$ cycling is that biological uptake is associated with negligible isotopic 551 fractionation of $\mathrm{Zn}$ isotopes. Experimental data that quantifies fractionation of $\mathrm{Zn}$ isotopes 552 upon biological uptake are scarce. The single relevant culturing experiment performed thus 553 far (John et al., 2007) suggests that the cellular quota of $\mathrm{Zn}$ in an oceanic diatom is $0.2-0.8 \%$ 554 lighter, depending on ambient free $\mathrm{Zn}^{2+}$ concentrations that are thought to drive different 555 uptake mechanisms, than the culture medium. This finding is consistent with a single study in 556 a Swiss lake (Peel et al., 2009), where organic-carbon-rich particulates produced during the 557 spring bloom are preferentially enriched in the light isotopes of $\mathrm{Zn}$, by an amount close to the 558 upper end of the isotopic separation implied by the culture experiments.

559 It is also theoretically possible that the intense vertical cycling of $\mathrm{Zn}$ in the oceans is 560 dominated by an abiotic process, such as scavenging onto particulate material in surface 561 waters and release back to the dissolved phase in the deep. Such a process has been invoked 562 to explain the vertical distributions of many other trace metals (for example aluminium, 563 thorium, see Bruland and Lohan., 2003 for a review). However, none of these metals show the 564 extreme surface to depth fractionation (up to 200 times lower concentrations in the photic 565 zone than the deep) that $\mathrm{Zn}$ does. Moreover, adsorption onto particulate surfaces is also 566 associated with isotopic fractionations that should also lead to deviations in the residual 567 dissolved pool (e.g. Pokrovsky et al., 2005; Gélabert et al., 2006; Balistrieri et al., 2008; 568 Juillot et al., 2008). 
569 Perhaps the strongest evidence for the biological cycling of $\mathrm{Zn}$ in the oceans is the well570 established close correlation between its depth distribution in the oceans and that of silica 571 (Bruland et al., 1980). The generally close association of Si and $\mathrm{Zn}$ has led to the suggestion 572 that both are regenerated together through the dissolution of diatom opal in the deep ocean. 573 However, culture experiments have shown that $\mathrm{Zn}$ contents of the opal phase of diatom cells 574 are very small, and that $97-99 \%$ of the $\mathrm{Zn}$ in diatoms is in organic material (Ellwood and 575 Hunter, 2000). Moreover, the $\mathrm{Zn} / \mathrm{Si}$ ratio of diatom opal is 1-2 orders of magnitude smaller 576 than in the deep Pacific (Bruland, 1980; Ellwood and Hunter, 2000; Lohan et al., 2002), also 577 arguing against the importance of the opal phase as the source of deep ocean Zn. One way to 578 explain the close correspondence of the deep regeneration profiles of $\mathrm{Si}$ and $\mathrm{Zn}$, that is also 579 consistent with the lack of $\mathrm{Zn}$ in the opal phase, is to invoke a $\mathrm{Zn}$-rich organic phase that is 580 intimately associated with the diatom frustule (c.f. Lohan et al., 2002). Thus, regenerated $\mathrm{Zn}$ 581 does not derive from the opal phase itself, but it is only exposed to oxidation in the deep ocean when the opal dissolves. It is well established that polysaccharides and proteins coat the 583 silica frustule of diatoms, and that these bear functional groups (e.g. amino, carboxyl) that 584 have a strong affinity for metal ions, including Zn (e.g. Gélabert et al., 2006).

585 These considerations have two obvious implications for the interpretation of the dissolved 586 phase $\mathrm{Zn}$ concentration and isotope data presented here. Firstly, they imply that there is more than one biologically-controlled pathway by which $\mathrm{Zn}$ is removed from the surface ocean 588 into proteins and enzymes within phytoplankton cells in all phytoplankton groups, and into an 589 organic phase that is, physically, intimately associated with the opal frustule of diatoms. 590 These two uptake mechanisms may be associated with different isotopic fractionations and 591 their relative importance will depend on local phytoplankton ecology, thus complicating 592 oceanic $\mathrm{Zn}$ isotopic data. Secondly, the regeneration of these two different pools, one at 593 shallower depths in association with intra-cellular organic matter, and one at greater depths 
594 coupled to opal dissolution, could lead to a partial decoupling, both between depth profiles of

$595 \mathrm{Zn}$ isotopes and those of $\mathrm{Zn}$ (and $\mathrm{Si}$ ) concentrations, and between the upper and deep ocean.

596 In the ensuing sections we discuss each of these implications, first for surface data and then

597 for the sub-surface and deep ocean.

\subsection{Controls on $\mathrm{Zn}$ in surface waters: relationships between $\mathrm{Zn}$ isotopes and $\mathrm{Si}$ and $\mathrm{Zn}$}

concentrations

600 The association between $\mathrm{Zn}$ and Si concentrations discussed in the previous section is seen in

601 the Southern Ocean data (Fig. 10a), but there is systematic structure in this relationship.

602 Moreover, $\mathrm{Zn}$ isotopes show no relationship at all with either $\mathrm{Si}$ (Fig. 10b) or $\mathrm{Zn}$

603 concentrations. We suggest that the structure apparent in the surface water Zn-Si relationship

604 in Fig. 10a, as well as the lack of any coherent relationship with $\mathrm{Zn}$ isotopes (Fig. 10b), may

605 both be a consequence of the multiple controls discussed in the previous section. For example,

606 on the Zn-Si plot (Fig. 10a) the upper ocean data (the surface (2-5m) samples with the filled

607 symbols, all profile data from depths above $100 \mathrm{~m}$, but down about $300 \mathrm{~m}$ at 104-2) clearly

608 separate into two arrays with different slopes, corresponding geographically to the Weddell

609 Gyre and the ACC (c,f a similar geographic split for Cd isotope data for these samples;

610 Abouchami et al., 2011). In most of the ACC zone, Zn-Si data for the upper water column

611 follow a tight linear correlation that comes close to going through the origin. In contrast,

612 surface data to the south of about $56^{\circ} \mathrm{S}$, within the Weddell Gyre, fall on a much steeper trend.

613 There is a transition zone in the southernmost $\mathrm{ACC}\left(53-55^{\circ} \mathrm{S}\right)$, where $\mathrm{Zn}$ concentrations

614 flatten out at 2.7-2.8 $\mathrm{nmol} \mathrm{kg}^{-1}$ while $\mathrm{Si}$ is variable (Fig. 10a, see also Fig. 9). Data for the

615 deeper levels (all data beneath about 300m) at all stations are at the high concentration end of

616 both trends. Geographically the top ends of both the surface trends, those closest in chemistry

617 to deep waters, are for surface waters in the upwelling zone centered on $58^{\circ} \mathrm{S}$. 
618 In terms of the ideas discussed in Section 6.1, it is noteworthy that diatoms peak in abundance 619 at $52-56^{\circ} \mathrm{S}$, just north of the upwelling zone (Alderkamp et al., 2010). Their proportion of the 620 phytoplankton assemblage then decreases steadily and monotonically northward as the Si 621 supply via horizontal advection from the upwelling zone decreases. The concomitant decrease 622 in $\mathrm{Zn}$ along the ACC trend might suggest that $\mathrm{Zn}$ concentrations are subject to the same 623 control. In the portion of the Weddell Gyre for which we present surface data, diatoms also 624 decrease in relative importance southwards to be replaced by a peak in haptophytes $(60 \%$ of 625 total phytoplankton at $62^{\circ} \mathrm{S}$; Alderkamp et al., 2010). Though the requirement of haptophytes 626 for $\mathrm{Zn}$ is not clear, the lesser importance of diatoms in this region, as well as lower 627 productivity overall, could explain both the high surface Si concentrations in the WG (Fig. 9) 628 and the steep slope of the $\mathrm{Zn} / \mathrm{Si}$ relationship in Figure 10a.

629 The impact of these changes in microbial ecology are hard to pinpoint at this early stage in the 630 development of oceanic $\mathrm{Zn}$ isotopes. But, for example, it may be that the relative lack of 631 correlation between $\mathrm{Zn}$ isotopes and Si concentrations (Fig. 10b) is a result of the dominance 632 of Zn removal into an organic phase, such as external polysaccharides that are ultimately 633 associated with the opal frustule, and that does not involve a strong isotopic fractionation. 634 Alternatively, any associated isotope fractionation would need to be more or less balanced by 635 uptake of $\mathrm{Zn}$ into the actual cell, with the preference for light isotopes that is expected for this 636 process, that has been observed in culture, and that has been inferred in lakes. It is noteworthy 637 that $\mathrm{Zn}$ attached to the external surfaces of diatoms in culture experiments (John et al., 2007) 638 is either unfractionated with respect to $\mathrm{Zn}$ in the medium (low free $\mathrm{Zn}^{2+}$ concentrations) or 639 slightly enriched in heavy isotopes (high free $\mathrm{Zn}^{2+}$ concentrations). Note that we do not 640 suggest that uptake of $\mathrm{Zn}$ into cells does not occur - rather that it may not be the dominant 641 mode of $\mathrm{Zn}$ removal from these Southern Ocean surface waters. Indeed, the next section will 642 argue for the regeneration of such an intra-cellular pool to explain the shallow sub-surface 
643 data.

\section{$644 \quad 6.3 \mathrm{Sub}$-surface $\mathrm{Zn}$ isotopic minima: the signature of regenerated intra-cellular $\mathrm{Zn}$}

645 The clearest and most consistent feature of the $\mathrm{Zn}$ isotopic data in the three depth profiles

646 (Fig. 6-8) is seen at the near surface, where data at around 50-70m are distinctly lighter than

647 the datum for the uppermost samples from the same depth profiles. Thus at PS71-163-1, the

$6489 \mathrm{~m}$ analysis gives $\delta^{66} \mathrm{Zn}=+0.63 \%$, while the analysis at $40 \mathrm{~m}$ gives $+0.27 \%$. At PS71-113-2

$649 \delta^{66} \mathrm{Zn}$ at $10 \mathrm{~m}$ is $+0.80 \%$ while at $74 \mathrm{~m}$ it is $+0.46 \%$. At PS71-104-2 $\delta^{66} \mathrm{Zn}=+0.46 \%$ at $15 \mathrm{~m}$

650 and is $+0.25 \%$ at $50 \mathrm{~m}$. Thus there is a fairly consistent $0.31 \pm 0.09 \%$ shift to lighter values in

651 the immediate sub-surface from the uppermost level measured. A similar shift is seen at the 652 only other relatively complete depth profile yet published. At the BATS station in the tropical 653 North Atlantic (Boyle et al. 2012), the surface datum is $0.28 \%$ heavier than that at $75 \mathrm{~m}$. $\mathrm{Zn}$

654 isotope data for the upper water column in the NE Pacific (Bermin et al., 2006) show a similar 655 pattern: the datum at $75 \mathrm{~m}$ is 0.2 per mil lighter than at the surface. At both BATS and the NE 656 Pacific there is then a more gradual move towards a heavier deep ocean value with depth. In 657 the depth profiles presented here this sub-surface minimum in $\delta^{66} \mathrm{Zn}$ is often quite abrupt, 658 which appears consistent with similarly abrupt changes in physical oceanographic parameters 659 to values that then characterize much of the deeper water column (e.g. Figure 6).

660 Thus, at this early stage, the shift from heavy $\mathrm{Zn}$ at the surface to lighter $\mathrm{Zn}$ in the immediate 661 sub-surface is developing into a consistent feature of oceanic $\mathrm{Zn}$ isotopes. In four out of the 662 five cases outlined above (BATS, NE Pacific, three Southern Ocean profiles), the horizon 663 with the isotopically-light $\mathrm{Zn}$ also has higher $\mathrm{Zn}$ concentrations than the surface datum. 664 Scavenging of $\mathrm{Zn}$ via adsorption onto particulate surfaces preferentially removes the heavy 665 isotope from solution (Maréchal et al., 2000; Pokrovsky et al., 2005; Gélabert et al., 2006; 666 Balistrieri et al., 2008; Juillot et al., 2008) and would thus leave an isotopically-light residual 
667 dissolved pool. Though the situation is complicated by the fact that upwelling advects $\mathrm{Zn}$ into 668 the upper ocean, the increasing $\mathrm{Zn}$ concentrations with depth do not appear to be consistent 669 with scavenging. Moreover, a scavenging origin for the light isotopes at around 50m leaves 670 open the cause, in two of the three depth profiles investigated in the Southern Ocean (PS71$671 \quad 113-2$ at $+0.8 \%$ and PS71-163-1 at $+0.67 \%$ ), of the distinctly heavy isotopic composition of 672 dissolved $\mathrm{Zn}$ right at the surface, heavier, for example, than any likely continental source 673 (Little et al., 2013), with nothing to date suggesting that such an input would be heavier than 674 about $+0.4 \%$. Thus, it seems probable that the enrichment of the light isotopes at $50-75 \mathrm{~m}$ are 675 coupled to a corresponding depletion at the surface. It is most likely then that this isotopic 676 fractionation is driven by a kinetic fractionation (John et al., 2007; Peel et al., 2009) 677 associated with uptake into a cellular pool (surface) and regeneration of that same pool in the 678 very shallow sub-surface.

679 Following the discussion in the sections 6.1 and 6.2, we stress again that uptake of $\mathrm{Zn}$ into the 680 cells of phytoplankton for metabolic use is likely to be only one of the processes by which $\mathrm{Zn}$ 681 is removed from the surface ocean. In the view presented here, a second process by which $\mathrm{Zn}$ 682 is associated with organic material within diatom frustules may often drive the bulk of the $\mathrm{Zn}$ 683 depletion in surface water, and we suggest that the lack of correlation between $\mathrm{Zn}$ isotopes 684 and $\mathrm{Si}$ concentrations (Fig. 10b) implies that this must occur with minimal isotopic 685 fractionation. Thus surface waters in the Southern Ocean do not develop the extremely heavy 686 residual $\mathrm{Zn}$ isotopic compositions that would be expected if the observed $\mathrm{Zn}$ depletion arose 687 purely from uptake into the interiors of cells with a kinetic isotopic fractionation. The crucial 688 point, however, is that the pool of $\mathrm{Zn}$ associated with the opal is regenerated only in the deep ocean, when the opal itself dissolves. Thus, the much shallower regeneration of the light intra690 cellular pool shows up as a distinctive feature of the water column at 50-75m, even though the 691 impact of it in the surface ocean is obscured by another process. 
692 We acknowledge that this interpretation of the $\mathrm{Zn}$ isotopic data is speculative at present, that

693 these qualitative ideas need to be tested experimentally and with further field data, and 694 particularly with at least a one-dimensional numerical model that parameterizes the key 695 processes. Such a model would also have to take account of vertical transport of $\mathrm{Zn}$ by 696 advection and diffusion, which would dampen the signature of the biological processes we 697 invoke. Such a one-dimensional model is beyond the scope of the present contribution, but is 698 something that is being actively pursued. As we show in the next section, however, the idea of 699 two broad mechanisms behind the depletion of $\mathrm{Zn}$ in surface waters, and different 700 lengthscales for the regeneration of the two resultant pools of $\mathrm{Zn}$ in the near surface and deep 701 ocean, also explain some otherwise puzzling features of deep Southern Ocean zinc 702 distributions, and the emerging pattern of $\mathrm{Zn}$ isotopes in the deep ocean more generally.

\section{6.4 The $\mathrm{Zn}$ isotopic composition of the deep ocean: regeneration of a distinct pool of $\mathrm{Zn}$}

704 As already stated, a striking feature of the Southern Ocean $\mathrm{Zn}$ isotope dataset is the 705 homogeneity of the deep ocean. Thus, apart from one outlying datum for the bottom sample at 706 PS71-163 (which may be affected by a sedimentary source), the 17 samples from $\geq 1000 \mathrm{~m}$ 707 yield $\delta^{66} \mathrm{Zn}=0.54 \pm 0.04$ (2 SE). Fig. 11 presents a summary of $\mathrm{Zn}$ isotopic composition data 708 from different parts of the world's deep oceans, from this study and from Boyle et al. (2012).

709 The datum plotted on Figure 11 for the deep Pacific is for the SAFE deep sample, one of the 710 intercalibration samples tabulated here (Table 1). Though data are admittedly still scarce, the 711 striking feature of Fig. 11 is the overall homogeneity of $\mathrm{Zn}$ isotopes in the deep ocean. 712 Beneath $1000 \mathrm{~m}$, the $\delta^{66} \mathrm{Zn}$ in three geographically widespread locations is essentially 713 identical, with an average and $2 \mathrm{sd}$ of $+0.53 \pm 0.14 \%$ ( $(2 \mathrm{SE}=0.03, \mathrm{n}=21)$.

714 In common with many oceanographic parameters, it is expected that the greatest variation in $715 \mathrm{Zn}$ isotopic compositions will be found in the upper ocean - it is here that the biogeochemical 
716 processes that impart the largest isotopic fractionations are expected to occur. The deep ocean, 717 on the other hand, is where $\mathrm{Zn}$ that is cycled between different phases (dissolved, biological

718 and inorganic particulates) in the upper ocean is largely returned to the dissolved phase (e.g.

719 Bruland, 1980). Thus it is perhaps no surprise that the deep ocean is relatively homogeneous.

720 It is more surprising that the deep North Atlantic and the deep North Pacific exhibit no

721 difference in $\delta^{66} \mathrm{Zn}$ (c.f. $\delta^{13} \mathrm{C}$, for example; Kroopnick, 1985) despite the rough factor of $4-5$

722 difference in total $\mathrm{Zn}$ concentrations between these two water masses.

723 It is very difficult to see how the drawdown of $\mathrm{Zn}$ in the surface ocean via cellular uptake

724 with a kinetic isotope fractionation similar to that implied by published culturing and field 725 studies (John et al., 2007; Peel et al., 2009) would not result in a significant isotopic 726 difference between the deep Atlantic and deep Pacific. On the other hand, the homogeneity of 727 deep ocean $\mathrm{Zn}$ isotope compositions is perfectly explicable if: (a) intra-cellular $\mathrm{Zn}$ is 728 regenerated in the shallow sub-surface as suggested in the previous section; (b) the dominant 729 process by which $\mathrm{Zn}$ is removed from the surface ocean is not via such intra-cellular uptake 730 but rather via a process that leads to its ultimate association with the opal frustules of diatoms, 731 one which is not associated with a significant isotopic fractionation; (c) these processes are 732 fast enough that mixing cannot eliminate the isotopic gradients. Such an explanation is, as 733 noted earlier, completely consistent with the similar patterns of $\mathrm{Si}$ and $\mathrm{Zn}$ regeneration in the 734 deep ocean, while accommodating the two additional observations deriving from culturing 735 studies and the water column data presented here: that $\mathrm{Zn}$ in diatoms is predominantly in an 736 organic phase (Ellwood and Hunter, 2000), and that intra-cellular uptake involves a 737 significant isotopic fractionation (John et al., 2007), one that is not consistent with the lack of 738 heavy $\mathrm{Zn}$ isotope signatures in the very $\mathrm{Zn}$-depleted surface ocean. 
741 In terms of the $\mathrm{Zn}$ isotopic cycle of the ocean as a whole, the relationship of oceanic dissolved

$742 \mathrm{Zn}$ isotope compositions to those of the inputs is clearly important. Thus the second feature

743 illustrated in Fig. 11 is the fact that the average deep ocean dissolved $\mathrm{Zn}$ isotopic composition 744 appears to be slightly heavier than the likely continental input (Little et al., 2013). Given the 745 higher $\mathrm{Zn}$ concentrations in the deep ocean relative to the surface, and the fact that $75 \%$ of the 746 volume of the oceans is also beneath $1000 \mathrm{~m}$, the deep ocean value must be very close to the 747 whole ocean average. For example, for the depth profiles in Table 2, as well as for that from 748 the North Atlantic in Boyle et al. (2012), the average of all the data, weighted by 749 concentration, is only 0.04 per mil less than the average of the data beneath $1000 \mathrm{~m}$, given 750 earlier as $0.53 \pm 0.03(2 \mathrm{SE}, \mathrm{n}=21)$.

751 The input flux to the oceans appears to be dominated by the dissolved riverine flux, with a 752 small but significant source from atmospheric aerosols (Little et al., 2013). A significant 753 hydrothermal input to the oceans has never been identified for $\mathrm{Zn}$ in depth profiles measured 754 close to ocean ridges (e.g. Bermin, 2006) in contrast to some other elements (e.g. German et 755 al., 1991 and Middag et al., 2011a for Mn; Klunder et al., 2011 for Fe). It appears that all the 756 (considerable) $\mathrm{Zn}$ emanating from hydrothermal systems is very quickly precipitated in 757 sulphides (German et al., 1991) near the source. The hydrothermal fluids that have been 758 measured (John et al., 2008) have a $\delta^{66} \mathrm{Zn}$ at $+0.24 \%$, slightly lighter than other inputs.

759 Thus an isotopically light sink from the dissolved pool appears to be required by the fact that 760 the dissolved pool is slightly heavier than the inputs. Light sinks from the ocean are well761 known for some other transition metals, such as Mo and $\mathrm{Cu}$ (e.g. Siebert et al., 2003; Barling 762 and Anbar, 2004; Little et al., 2013) but none of these help with the $\mathrm{Zn}$ issue. For example, $\mathrm{Zn}$ 763 isotopes in Fe-Mn crusts and nodules are universally heavier than deep seawater (Maréchal et 764 al., 2000; Little et al. 2013), implying not only that this output does not represent the required 
765 light sink, but also that if this is a significant output the requirement for a light sink is 766 increased. The single study available of oceanic carbonate (Pichat et al., 2003) suggests that 767 this small sink is also isotopically heavy. The ideas presented in earlier sections suggest that 768 the diatom opal sink of $\mathrm{Zn}$ probably closely reflects surface seawater itself and will also be 769 heavier than the inputs (c.f. Andersen et al., 2011), while Zn sorption to organic material 770 should also be either the same as seawater or slightly isotopically heavy (Gélabert et al. 2006; 771 John et al., 2007).

772 The only important removal pathway from the dissolved pool in the oceans that is likely to be 773 isotopically light is the pool of $\mathrm{Zn}$ that is taken up intra-cellularly by phytoplankton. As noted 774 in previous sections, a single culturing study (John et al., 2007) has demonstrated that diatoms 775 take up the light isotopes of $\mathrm{Zn}$ such that $\Delta_{\text {seawater-diatom cell }}=+0.2$ to +0.8 , with the 776 fractionation varying systematically with the free $\mathrm{Zn}^{2+}$ concentration of the medium. A study 777 of a Swiss lake (Peel et al. 2009) has demonstrated that sinking particulates associated with 778 the summer algal bloom have a $\delta^{66} \mathrm{Zn} 0.8 \%$ lighter than the water column. Moreover, 779 Andersen et al. (2011) invoked the same uptake of light $\mathrm{Zn}$ isotopes into phytoplankton 780 organic material to explain the progressively heavier isotopic signature of diatom opal, which 781 these authors interpreted to be recording surface seawater, as upwelled $\mathrm{Zn}$ is progressively 782 depleted in the surface waters of the Pacific Sub-Antarctic zone of the Southern Ocean. We 783 have suggested earlier that it is regeneration of this pool that yields the light $\mathrm{Zn}$ isotopic 784 composition of the shallow sub-surface in the Southern Ocean and elsewhere.

785 It thus seems likely that the portion of the isotopically light cellular $\mathrm{Zn}$ that survives 786 regeneration and is buried in sediments could represent the sink that seems to be required by 787 the oceanic $\mathrm{Zn}$ cycle as we understand it thus far. $\mathrm{Zn}$ isotopic analysis of organic-rich 788 sediments may provide a means of testing this suggestion. Though fraught with uncertainty, a 
789

790

791

792

793

794

795

796

797

798

799

800

801

802

803

804

805

806

807

808

simple calculation can provide a preliminary assessment of its feasibility. Little et al. (2013) suggest that the magnitude of a missing light sink must be around $3 \pm 2 \times 10^{8}$ mol $\mathrm{yr}^{-1}$, depending on its isotopic composition. Data on the $\mathrm{Zn} / \mathrm{C}$ ratio of marine phytoplankton are scarce but those in Ho et al. (2003) for a variety of cultured organisms suggest that it is of the order of $0.6 \times 10^{-6} \mathrm{~mol} / \mathrm{mol}$. Field data for plankton tows in the same paper show $\mathrm{Zn} / \mathrm{P}$ ratios up to 5 times greater than the cultured organisms. These data would imply a carbon burial rate to achieve the required $\mathrm{Zn}$ sink of $0.3-8 \times 10^{13} \mathrm{~mol} \mathrm{yr}^{-1}$. Unfortunately large uncertainties on this estimate derive from the input parameters, but the range does span published estimates of carbon burial rates at $1-2 \times 10^{13} \mathrm{~mol} \mathrm{yr}^{-1}$ (e.g. Hedges and Keil., 1995).

\section{CONCLUDING REMARKS}

We have reported the first full depth profiles for dissolved $\mathrm{Zn}$ isotopes in the ocean, as well as data for a surface transect along the zero meridian in the Atlantic sector of the Southern Ocean. The new isotopic data, taken together with data for the deep North Pacific and published data for the North Atlantic, exhibit three principal features. The first is the homogeneity of the deep ocean, such that the data presented here for beneath $1000 \mathrm{~m}$, in combination with more limited data from the North Pacific and North Atlantic, have a $\delta^{66} \mathrm{Zn}=$ $+0.53 \pm 0.14 \%$ o $(2 \mathrm{SE}=0.03, \mathrm{n}=21)$. Secondly, and though there are both heavy and light isotopic values in the surface Southern Ocean, there is no systematic shift towards heavy isotopic compositions as would be expected (John et al., 2007; Peel et al., 2009) if the wellestablished $\mathrm{Zn}$ drawdown in the surface ocean is achieved dominantly through intra-cellular uptake of Zn. Thirdly, surface values are always heavier than data for the shallow sub-surface (40-80m), both in the dataset presented here and in two published partial depth profiles from the North Atlantic and North Pacific (Bermin et al., 2006; Boyle et al., 2012). 
813 These new $\mathrm{Zn}$ isotope data are consistent with a scenario whereby $\mathrm{Zn}$ removal from the

814 surface ocean occurs via two processes, a dominant one that does not involve an isotopic

815 fractionation and a lesser one that preferentially removes the light isotope. We suggest that the

816 dominant process is the incorporation of $\mathrm{Zn}$ into organic matter associated with diatom

817 frustules, while the second is the metabolic uptake of $\mathrm{Zn}$ into the cells of all phytoplankton.

818 Such a hypothesis is consistent with the data presented here, as well as some key observations

819 that have been made about the oceanic $\mathrm{Zn}$ cycle in previous work. Firstly, dissolved $\mathrm{Zn}$

820 concentrations in this study and elsewhere are closely tied to $\mathrm{Si}$, but structure in the

821 correlations for surface water (Fig. 10a) suggests a dependence on microbial ecology, in

822 particular the dominance or not of opal-building organisms in the phytoplankton assemblage.

823 The well-established observation of strong Si-Zn concentration correlations is coupled to the

824 fact that there is no systematic relationship at all between $\mathrm{Si}$ and $\mathrm{Zn}$ isotopes (Fig. 10b),

825 implying that the removal of $\mathrm{Zn}$ coupled to $\mathrm{Si}$ removal involves little or no isotopic

826 fractionation. On the other hand, increases in $\mathrm{Zn}$ concentration with depth down to $80 \mathrm{~m}$ are

827 associated with distinctly lighter isotopic compositions than the rest of the water column,

828 including the overlying photic zone. We suggest that this is the signature of the regeneration

829 of intra-cellular zinc, while the main increase in $\mathrm{Zn}$ concentrations in the deep ocean, closely

830 tied to $\mathrm{Si}$, is the result of the regeneration of organic material intimately associated with

831 diatom frustules, that is only re-mobilised when the opal itself dissolves (c.f. Lohan et al., 832 2002).

833 The scenario outlined above is consistent with what we know about the interactions between

$834 \mathrm{Zn}$ and its isotopes, Si and biology from experiments and field studies. For example, culture 835 studies have demonstrated that the $\mathrm{Zn}$ content in the opal phase of frustules is very small 836 (Ellwood and Hunter, 2000), about $1-3 \%$ of the total $\mathrm{Zn}$ in diatoms with the rest associated 837 with one or more organic phases. In addition, the $\mathrm{Zn} / \mathrm{Si}$ ratio of the deep ocean is 1-2 orders of 
838 magnitude greater than in diatom opal (e.g. Bruland, 1980; Lohan et al., 2002). Both of these 839 constraints have rendered the close association between $\mathrm{Si}$ and $\mathrm{Zn}$ concentrations in the deep 840 ocean a real conundrum. A solution to this puzzle is provided by the fact that polysaccharides 841 and proteins coat the silica frustule of diatoms, and that these bear functional groups (e.g. 842 amino, carboxyl) that have a strong affinity for metal ions, including Zn (e.g. Gélabert et al., 843 2006). Culture experiments have also shown that the $\mathrm{Zn}$ associated with these organic 844 substances (Gélabert et al., 2006) is isotopically identical to $\mathrm{Zn}$ in the culture medium at free $845 \mathrm{Zn}^{2+}$ concentrations equivalent to those found in the surface ocean (John et al., 2007). In our 846 proposed scenario, it is this $\mathrm{Zn}$ that is regenerated with $\mathrm{Si}$, but only when the opal frustule 847 itself dissolves, in the deep ocean. The fact that the uptake of this pool of $\mathrm{Zn}$ involves little 848 isotope fractionation explains the lack of a relationship between $\mathrm{Si}$ concentrations and $\mathrm{Zn}$ 849 isotopes in the portion of the Southern Ocean studied here, where diatoms are an important 850 part of the phytoplankton population. The relative dominance of this process would also 851 explain the fact that the deep Atlantic, the deep Southern Ocean and the deep Pacific are 852 isotopically identical for Zn (Boyle et al., 2012; this study). On the other hand, both culture 853 experiments and field data demonstrate that uptake of $\mathrm{Zn}$ into the interiors of cells for 854 metabolic purposes shows the expected preference for the light isotopes (John et al., 2007; 855 Peel et al., 2009). We further suggest, therefore, that this represents a different process, a pool 856 that is regenerated at much shallower levels, and one that explains the light isotopic signature 857 seen at 40-80m in the Southern Ocean, the North Atlantic and the NE Pacific.

858 Clearly these qualitative ideas, though for the first time yielding a wholly consistent picture of 859 the oceanic Zn cycle, need to be tested. They imply, in particular, a decoupling of the shallow 860 and deep ocean for $\mathrm{Zn}$, with the isotopic characteristics of the two being determined by 861 different processes. A quantitative 1D model is required to ascertain, for example, whether the 862 light signal in the shallow sub-surface can be maintained against upward advection of deep 
863 waters in the Southern Ocean. A prediction of these ideas would be that the vertical 864 component of the oceanic cycle of $\mathrm{Zn}$ and its isotopes would differ in regions where diatoms 865 dominate, as opposed to where non-silica-building organisms are the main contributors to the 866 phytoplankton assemblage.

867 In addition, we have addressed the mass balance of the whole ocean, using the data in this 868 paper, published data for $\mathrm{Zn}$ isotopes in other parts of the ocean, and data on the inputs and 869 outputs (Little et al., 2013). The large and homogeneous deep ocean $\mathrm{Zn}$ reservoir is about 0.2 $870 \%$ heavier than our current best estimate of the inputs of $\mathrm{Zn}$ to the ocean, so that an

871 isotopically light sink is required for the whole ocean isotopic mass balance. The sinks that

872 have been characterised, in contrast, are all heavier than the inputs. We advance the working

873 hypothesis that it is the burial of isotopically light $\mathrm{Zn}$ in cellular organic matter that represents 874 the light sink from the oceanic dissolved pool. This idea can also be tested through the 875 isotopic analysis of organic-rich sediments.

\section{ACKNOWLEDGEMENTS}

878 We gratefully acknowledge the captain, officers and entire crew of the P. S. Polarstern. This 879 work was supported by a UK government Overseas Research Scholarship to YZ and a 880 Leverhulme Research Fellowship to DV. The comments of Associate Editor Mark 881 Rehkämper and those of three anonymous reviewers forced us to think harder about the data 882 and have genuinely turned this into a better paper. 
884

885

886

887

888

889

890

891

892

893

894

895

896

897

898

899

900

901

902

903

904

905

906

907

\section{REFERENCES}

Abouchami W., Galer S.J.G., de Baar H.J.W., Alderkamp A.C., Middag R., Laan P., Feldmann H. and Andreae M.O. (2011) Modulation of the Southern Ocean cadmium isotope signature by ocean circulation and primary productivity. Earth Planet. Sci. Lett. 305, 83-91. Alderkamp A.C., De Baar H.J.W., Visser R.J.W. and Arrigo K.R. (2010) Can photoinhibition control phytoplankton abundance in deeply mixed water columns of the Southern Ocean? Limnol. Oceanogr. 55, 1248-1264.

Altabet M.A. and Francois R. (1994) Sedimentary nitrogen isotopic ratio records surface ocean $\mathrm{NO}_{3}$ - utilization. Global. Biogeochem. Cyc. 8, 103-116.

Andersen M.B., Vance D., Archer C., Anderson R.F., Ellwood M.J. and Allen C.S. (2011)

The $\mathrm{Zn}$ abundance and isotopic composition of diatom frustules, a proxy for $\mathrm{Zn}$ availability in ocean surface seawater. Earth Planet. Sci. Lett. 301, 137-145.

Archer C. and Vance D. (2004) Mass discrimination correction in multiple-collector plasma source mass spectrometry: an example using $\mathrm{Cu}$ and $\mathrm{Zn}$ isotopes. J. Anal. At. Spectrom. 19, 656-665.

Balistrieri L.S., Borrok D.M., Wanty R.B. and Ridley W.I. (2008) Fractionation of Cu and Zn isotopes during adsorption onto amorphous Fe(III) oxyhydroxide: experimental mixing of acid rock drainage and ambient river water. Geochim. Cosmochim. Acta 72, 311-328.

Barling J. and Anbar A.D. (2004) Molybdenum isotope fractionation during adsorption by manganese oxides. Earth Planet. Sci. Lett. 217, 315-329.

Bermin J., Vance D., Archer C. and Statham P.J. (2006) The determination of the isotopic composition of $\mathrm{Cu}$ and $\mathrm{Zn}$ in seawater. Chem. Geol. 226, 280-297.

Bermin J. (2006) Determination of the isotopic composition of $\mathrm{Cu}$ and $\mathrm{Zn}$ in seawater. $\mathrm{PhD}$ dissertation, Royal Holloway, University of London. 
908 Boyd P.W. and Elwood M.J. (2010) The biogeochemical cycle of iron in the ocean. Nat. 909 Geosci. 3, 675-682.

910 Boyd P.W and 35 others (2000) A mesoscale phytoplankton bloom in the polar Southern

911 Ocean stimulated by iron fertilization. Nature 407, 695-702.

912 Boyle E.A. and 20 others (2012) Geotraces IC1 (BATS) contamination-prone trace element

913 isotopes $\mathrm{Cd}, \mathrm{Fe}, \mathrm{Pb}, \mathrm{Zn}, \mathrm{Cu}$ and Mo intercalibration. Limnol. Oceanogr. - Methods 10, 653914665.

915 Brand L.E., Sunda W.G. and Guillard R.R.L. (1983) Limitation of marine phytoplankton 916 reproductive rates by zinc, manganese and iron. Limnol. Oceanogr. 28, 1182-1198.

917 Bruland K.W. (1980) Oceanographic distributions of cadmium, zinc, nickel, and copper in the 918 North Pacific. Earth Planet. Sci. Lett. 47(2), 176-198.

919 Bruland K.W. (1989) Complexation of zinc by natural organic ligands in the Central North 920 Pacific. Limnol. Oceanogr. 34(2), 269-285.

921 Bruland K.W., Lohan M.C. (2003) Controls of Trace Metals in Seawater. In Treatise on 922 Geochemistry, vol. 6 (ed H. Elderfield). Elsevier, Amsterdam, pp. 23-47.

923 Buitenhuis E.T., Timmermans K.R. and de Baar H. (2003) Zinc-bicarbonate colimitation of 924 Emiliania huxleyi. Limnol. Oceanogr. 48(4), 1575-1582.

925 Buma A.G.J., de Baar H.J.W., Nolting R.F. and van Bennekom A.J. (1991) Metal enrichment 926 experiments in the Weddell-Scotia Seas: effects of $\mathrm{Fe}$ and $\mathrm{Mn}$ on various plankton 927 communities. Limnol. Oceanogr. 36, 1865-1878.

928 Cloquet C., Carignan J. and Libourel, G. (2006) Isotopic composition of $\mathrm{Zn}$ and $\mathrm{Pb}$ 929 atmospheric depositions in an urban/periurban area of northeastern France. Env. Sci. Tech. 40, $930 \quad 6594-6600$.

931 Coale K.H., Gordon R.M. and Wang X. (2005) The distribution and behavior of the dissolved 932 and particulate iron and zinc in the Ross Sea and Antarctic Circumpolar Current along $70^{\circ} \mathrm{W}$. 
Deep-Sea Res. 52, 295-318.

934 Crawford D.W., Lipsen M.S., Purdie D.A., Lohan M.C., Statham P.J., Whitney F.A., Putland 935 J.N., Johnson W.K., Sutherland N., Peterson T.D., Harrison P.J. and Wong C.S. (2003) 936 Influence of zinc and iron enrichments on phytoplankton growth in the northeastern subarctic 937 Pacific. Limnol. Oceanogr. 48, 1583-1600.

938 Croot P.L., Baars O. and Streu P. (2011) The distribution of dissolved zinc in the Atlantic 939 sector of the Southern Ocean. Deep-Sea Res. II. 58, 2707-2719.

940 Cullen J.T. (1991) Hypotheses to explain high nutrient conditions in the open sea. Limnol. 941 Oceanogr. 36, 1579-1599.

942 de Baar H.J.W., Buma A.G.J., Nolting R.F., Cadée G.C., Jacques G. and Tréguer P.J. (1990)

943 On iron limitation of the Southern Ocean: experimental observations in the Weddell and 944 Scotia Seas. Mar. Ecol. Prog. Ser. 65, 105-122.

945 de Baar H., de Jong J.T.M., Bakker D.C.E., Löscher B.M., Veth C., Bathmann U. and 946 Smetacek V. (1995) Importance of iron for plankton blooms and carbon dioxide drawdown in 947 the Southern Ocean. Nature 373, 412-415.

948 de Baar H.J.W. and 33 others (2005) Synthesis of iron fertilization experiments: from the Iron 949 Age in the Age of Enlightenment. J. Geophys. Res. 110, C09S16, doi: $950 \quad 10.1029 / 2004 J C 002601$.

951 de Baar H., Timmermans K.R., Laan P., de Porto H.H., Ober S., Blom J.J., Bakker M.C., 952 Schilling J., Sarthou G., Smit M.G. and Klunder M. (2008) Titan: a new facility for ultraclean 953 sampling of trace elements and isotopes in the deep oceans in the international Geotraces 954 program. Mar. Chem. 111, 4-21.

955 De La Rocha C.L., Brzezinski M.A., DeNiro M.J. and Shemesh A. (1998) Silicon-isotope 956 composition of diatoms as an indicator of past oceanic change. Nature 395, 680-683.

957 Donat J.R., Bruland K.W. (1990) A comparison of two voltammetric techniques for 
958 determining zinc speciation in northeast Pacific Ocean waters. Mar. Chem. 28, 301-323.

959 Ellwood M.J. and Hunter, K. (2000) The incorporation of zinc and iron into the frustule of the 960 marine diatom Thalassiosira pseudonana. Limnol. Oceanogr. 45, 1517-1524.

961 Ellwood M.J. and van den Berg C.M.G. (2000) Zinc speciation in the Northeastern Atlantic 962 Ocean. Mar. Chem. 68, 295-306.

963 Fahrbach E. and de Baar H. (2010) The Expedition of the Research Vessel "Polarstern" to the 964 Antarctic in 2008 (ANT-XXIV/3). Reports on Polar and Marine Research 965 hdl:10013/epic.34050.

966 Gélabert A., Pokrovsky O.S., Viers J., Schott J., Boudou A and Feurtet-Mazel A. (2006) 967 Interaction between zinc and freshwater and marine diatom species: Surface complexation 968 and $\mathrm{Zn}$ isotope fractionation. Geochim. Cosmochim. Acta 70, 839-857.

969 German C.R., Fleer A.P., Bacon M.P. and Edmond J.M. (1991) Hydrothermal scavenging at 970 the Mid Atlantic Ridge: Radionuclide distributions. Earth Planet. Sci. Lett. 107, 101-114.

971 Grasshoff K., Fleming K. and Ehrhardt M. (1999) Methods of Seawater Analysis. Verlag 972 Wiley-VCH, Weinheim, 632pp.

973 Hassler C.S., Sinoir M., Clementson L.A. and Butler E.C.V. (2012) Exploring the link 974 between micro-nutrients and phytoplankton in the Southern Ocean during the 2007 austral 975 summer. Front Microbiol. 3, 202.

976 Hedges J.I. and Keil R.G. (1995) Sedimentary organic matter preservation: an assessment and 977 speculative synthesis. Mar. Chem. 49, 81-115.

978 Ho T.-Y., Quigg A., Finkel Z.V., Milligan A.J., Wyman K., Falkowski P.G. and Morel 979 F.M.M. (2003) The elemental composition of some marine phytoplankton. J. Phycol. 39, $980 \quad 1145-1159$.

981 John S.G, Geis R.W., Saito M.A. and Boyle E.A. (2007) Zinc isotope fractionation during 982 high-affinity and low-affinity zinc transport by the marine diatom Thalassiosira oceanica. 
983

984

985

986

987

988

989

990

991 1004 column of the subarctic North East Pacific. Deep-Sea Res. II 49, 5793-5808.

1005

Limnol. Oceanogr. 52, 2710-2714.

John S.G., Rouxel O.J., Craddock P.R., Engwall A.M. and Boyle E.A. (2008) Zinc stable isotopes in seafloor hydrothermal vent fluids and chimneys. Earth Planet. Sci. Lett. 269, 1728.

Juillot F., Marechal C., Ponthieu M., Cacaly S., Morin G., Benedetti M., Hazemann J.L., Proux O. and Guyot F. (2008) Zn isotopic fractionation caused by sorption on goethite and 2Lines ferrihydrite. Geochim. Cosmochim. Acta 72, 4886-4900.

Kingston H.M., Barnes I.L., Brady T.J. and Rains T.C. (1978) Separation of eight transition elements from alkali and alkaline earth elements in estuarine and seawater with chelating resin and their determination by graphite furnace atomic absorption spectrometry. Anal. Chem. 50, 2065-2070.

Klunder M.B., Laan P., Middag R., de Baar H.J.W. and van Oiijen J.C. (2011) Dissolved iron in the Southern Ocean (Atlantic sector). Deep-Sea Res. II 58, 2678-2694.

Kroopnick P.M. (1985) The distribution of ${ }^{13} \mathrm{C}$ of $\Sigma \mathrm{CO}_{2}$ in the world oceans. Deep-Sea Res. I. 32, 57-84.

Lippard S.J. and Berg J.M. (1994) Principles of Bioinorganic Chemistry. University Science books, Mill Valley, CA, USA.

Little S.H., Vance D., Walker-Brown C. and Landing W.M. (2013) The oceanic mass balance of $\mathrm{Cu}$ and $\mathrm{Zn}$ isotopes, investigated by analysis of their inputs and oxic output in ferromanganese crusts. Geochim. Cosmochim. Acta, submitted.

Lohan M.C., Statham P.J. and Crawford D.W. (2002) Total dissolved zinc in the upper water

Löscher B.M. (1999) Relationships among Ni, Cu, Zn and major nutrients in the Southern Ocean. Mar. Chem. 6, 67-102. 
1007 Maréchal C.N., Télouk P. and Albarède F. (1999) Precise analysis of copper and zinc isotopic 1008 compositions by plasma-source mass spectrometry. Chem. Geol. 156, 251-273.

1009 Maréchal C.N., Nicolas E., Douchet C. and Albarède F. (2000) Abundance of zinc isotopes as 1010 a marine biogeochemical tracer. Geochem. Geophys. Geosyst. 1, 1999 GC000029.

1011 Marinov I., Gnanadesikan A., Toggweiler J.R. and Sarmiento J.L. (2006) The Southern Ocean 1012 biogeochemical divide. Nature 441, 964-967.

1013 Martin J.H., Gordon R.M., Fitzwater S. and Broenkow W.W. (1989) VERTEX: 1014 phytoplankton/iron studies in the Gulf of Alaska. Deep-Sea Res. 36, 649-680.

1015 Martin J.H., Fitzwater S.E and Gordon R.M. (1990) Iron deficiency limits phytoplankton 1016 growth in Antarctic Waters. Global. Biogeochem. Cyc. 4, 5-12.

1017 Middag R., de Baar H.J.W., Laan P., Cai P.H. and van Ooijen J. (2011a) Dissolved 1018 manganese in the Atlantic sector of the Southern Ocean. Deep-Sea Res. II 58, 2661-2677

1019 Middag R., van Slooten C., de Baar H.J.W. and Laan P. (2011b) Dissolved aluminium in the 1020 Southern Ocean. Deep-Sea Res. II 58, 2647-2660.

1021 Minas H.J., Minas M. and Packard T.T. (1986) Productivity in upwelling areas deduced from 1022 hydrographic and chemical fields. Limnol. Oceanogr. 31, 1182-1206.

1023 Mitchell B.G., Brody E.A., Holm-Hansen O., McClain C. and Bishop J. (1991) Light 1024 limitation of phytoplankton biomass and macronutrient utilization in the Southern Ocean. 1025 Limnol. Oceanogr. 36, 1662-1677.

1026 Morel F.M.M., Reinfelder J.R., Chamberlain C.P., Roberts S.B., Lee J.G. and Yee D. (1994) 1027 Zinc and carbon co-limitation of marine phytoplankton. Nature 369, 740-742.

1028 Orsi A.H., Whitworth III T. and Nowlin W.D. (1995) On the meridional extent and fronts of 1029 the Antarctic Circumpolar Current. Deep-Sea Res. 42, 641-673.

1030 Peel K., Weiss D. and Sigg L. (2009) Zinc isotope composition of settling particles as a proxy 1031 for biogeochemical processes in lakes: insights from the eutrophic Lake Greifen, Switzerland. 
1032

1033 Pichat S., Douchet C. and Albarede F. (2003) Zinc isotope variations in deep-sea carbonates 1034 from the eastern equatorial Pacific over the last 175 ka. Earth Planet. Sci. Lett. 210, 167-178.

1035 Pokrovsky O.S., Viers J. and Freydier R. (2005) Zinc stable isotope fractionation during its 1036 adsorption on oxides and hydroxides. J. Colloid. Interf. Sci. 291, 192-200.

1037 Queguiner B., Treguer P., Peeken I. and Scharek R. (1997) Biogeochemical dynamics and the 1038 silicon cycle in the Atlantic sector of the Southern Ocean during austral spring 1992. Deep1039 Sea Res. II 44, 69-89.

1040 Scharek R., van Leeuwe M.A. and de Baar H.J.W. (1997) Responses of Southern Ocean 1041 phytoplankton to addition of trace metals. Deep-Sea Res. II, 44, 209-227

1042 Schlitzer R. (2002) Ocean Data View, http://www.awi-bremerhaven.de/GEO/ODV.

1043 Shaked Y., Xu Y., Leblanc K. and Morel F.M.M. (2006) Zinc availability and alkaline 1044 phosphatase activity in Emiliania huxleyi: Implications for Zn-P co-limitation in the ocean. 1045 Limnol. Oceanogr. 51, 299-309.

1046 Siebert C., Nägler T., von Blanckenburg F. and Kramers J.D. (2003) Molybdenum isotope 1047 records as a potential new proxy for paleoceanography. Earth Planet. Sci. Lett. 211, 159-171.

1048 Sinoir M., Butler E.C.V., Bowie A.R., Mongin M., Nesterenko P.N., and Hassler C.S. (2012) 1049 Zinc marine biogeochemistry in seawater: a review. Mar. Freshwater. Res. 63, 644-657.

1050 Sunda W.G. and Huntsman S.A. (1992) Feedback interactions between zinc and 1051 phytoplankton in seawater. Limnol. Oceanogr. 37, 25-40.

1052 Sunda W.G. and Huntsman S.A. (1995) Cobalt and zinc inter-replacement in marine 1053 phytoplankton: biological and geochemical implications. Limnol. Oceanogr. 40, 1404-1407.

1054 Sunda W.G. and Huntsman S.A. (1997) Interrelated influence of iron, light and cell size on 1055 marine phytoplankton growth. Nature 390, 389-392. 
1056 Sunda W.G. and Huntsman S.A. (2005) Effect of $\mathrm{CO}_{2}$ supply and demand on zinc uptake and 1057 growth limitation in a coastal diatom. Limnol. Oceanogr. 50, 1181-1192.

1058 Weiss D.J., Mason T.F.D., Zhao F.J., Kirk G.J.D., Coles B.J. and Horstwood M.S.A. (2005)

1059 Isotopic discrimination of zinc in higher plants. New. Phytol. 165, 703-710.

$1060 \mathrm{Wu}$ J. and Boyle E.A. (1998) Determination of iron in seawater by high-resolution isotope 1061 dilution inductively coupled plasma mass spectrometry after $\mathrm{Mg}(\mathrm{OH})_{2}$ coprecipitation. Anal. 1062 Chim. Acta 367, 183-191.

1063 
1064 Table 1: Zn isotopic and concentration analyses of intercalibration samples obtained from the 1065 Bruland laboratory at Santa Cruz.

\begin{tabular}{|c|c|c|c|c|c|c|}
\hline Sample ID & $\begin{array}{l}\text { Depth } \\
(\mathrm{m})\end{array}$ & $\begin{array}{c}{[\mathrm{Zn}]} \\
(\mathrm{nmol} / \mathrm{kg}) \\
\end{array}$ & $\begin{array}{c}\delta^{66} \mathrm{Zn} \\
(\%) \\
\end{array}$ & 2 sigma & $\begin{array}{c}\text { Total } \mathrm{Zn} \text { from ID } \\
(\mathrm{ng})\end{array}$ & $\begin{array}{l}\text { Yield } \\
(\%) \\
\end{array}$ \\
\hline $\mathrm{SAFe} \mathrm{D} 2^{\mathrm{a}}$ & 1000 & 7.66 & 0.52 & 0.03 & 103 & 91 \\
\hline SAFe D1 & 1000 & 7.68 & 0.56 & 0.03 & 85 & 91 \\
\hline SAFe D2 & 1000 & 7.40 & 0.52 & 0.03 & 76 & 96 \\
\hline SAFe D2 & 1000 & 7.38 & 0.50 & 0.04 & 74 & 95 \\
\hline SAFe $S^{b}$ & Surface & 0.051 & & & 17 & 85 \\
\hline SAFe S & Surface & 0.052 & & & 17 & 91 \\
\hline SAFe S & Surface & 0.050 & & & 17 & 59 \\
\hline SAFe S & Surface & 0.049 & & & 16 & 60 \\
\hline $\mathrm{GSC} 32^{\mathrm{c}}$ & Surface & 1.35 & 0.08 & 0.04 & 48 & 99 \\
\hline $\mathrm{GSC} 303^{\mathrm{c}}$ & Surface & 1.37 & 0.18 & 0.06 & 47 & 97 \\
\hline
\end{tabular}

${ }^{a}$ SAFe deep samples (central North Pacific) obtained from Geoffrey Smith (University of California, Santa Cruz). Each line on the table is for a separate analysis from two different bottles (D1 or D2).

${ }^{\mathrm{b}} \mathrm{SAFe}$ surface samples (central North Pacific) obtained from Geoffrey Smith (University of California, Santa Cruz). Each line is for a separate analysis from four different 4 litre bottles. These analyses were done at a stage when we had not developed the methodology fully for small samples and isotopic data were not obtained. 
1075 Table 2: $\mathrm{Zn}$ concentration $(\mathrm{nmol} / \mathrm{kg})$ and $\delta^{66} \mathrm{Zn}$ for three vertical profiles in the Atlantic sector 1076 of the Southern Ocean.

\begin{tabular}{|c|c|c|c|c|c|c|c|}
\hline IPY ID & $\begin{array}{l}\text { Depth } \\
\text { (m) }\end{array}$ & $\begin{array}{c}{[\mathrm{Zn}]} \\
(\mathrm{nmol} / \mathrm{kg})\end{array}$ & $\begin{array}{c}\delta^{66} \mathrm{Zn} \\
(\% 0)\end{array}$ & 2 sigma $^{1}$ & $\begin{array}{l}\text { Total } \mathrm{Zn}^{2} \text { in } \\
\text { analysis (ng) }\end{array}$ & $\begin{array}{l}\text { Yield } \\
(\%)\end{array}$ & $\begin{array}{c}{[\mathrm{Si}]^{3}} \\
(\mu \mathrm{mol} / \mathrm{kg})\end{array}$ \\
\hline
\end{tabular}

$\begin{array}{lccccccr}\text { Station PS71-104-2 } & \left.\mathbf{( 4 7}^{\circ} \mathbf{3 9 . 3 6} \mathbf{S} \mathbf{S} \mathbf{4}^{\mathbf{0}} \mathbf{1 5 . 7} \mathbf{} \mathbf{E}\right) & & & & & \\ \text { PS71-104-2-24 } & 15 & 0.32 & 0.47 & 0.07 & 51 & 72 & 1.86 \\ \text { PS71-104-2-22 } & 50 & 0.62 & 0.25 & 0.05 & 86 & 80 & 1.86 \\ \text { PS71-104-2-20 } & 101 & 0.71 & 0.43 & 0.05 & 103 & 77 & 5.66 \\ \text { PS71-104-2-18 } & 202 & 1.03 & 0.41 & 0.04 & 129 & 74 & 10.2 \\ \text { PS71-104-2-16 } & 301 & 2.10 & 0.47 & 0.04 & 68 & 95 & 20.4 \\ \text { PS71-104-2-14 } & 399 & 2.45 & 0.44 & 0.05 & 79 & 99 & 28.1 \\ \text { PS71-104-2-11 } & 998 & 5.35 & 0.44 & 0.06 & 79 & 99 & 65.1 \\ \text { PS71-104-2-9 } & 1500 & 5.33 & 0.43 & 0.05 & 78 & 105 & 68.7 \\ \text { PS71-104-2-8 } & 1748 & 4.88 & 0.48 & 0.05 & 53 & 98 & 70.7 \\ \text { PS71-104-2-7 } & 1997 & 4.88 & 0.50 & 0.07 & 49 & 101 & 72.0 \\ \text { PS71-104-2-6 } & 2499 & 5.83 & 0.51 & 0.05 & 54 & 97 & 89.1 \\ \text { PS71-104-2-5 } & 3002 & 6.16 & 0.60 & 0.06 & 56 & 96 & 101 \\ \text { PS71-104-2-3 } & 4006 & 8.04 & 0.61 & 0.05 & 83 & 99 & 118 \\ \text { PS71-104-2-2 } & 4202 & 7.03 & 0.54 & 0.06 & 70 & 92 & 119\end{array}$

\section{Station PS71-113-2 $\left(5^{\circ}{ }^{\circ} 59.828^{\prime} \mathrm{S}, \mathbf{0 . 2}^{\circ} 0.05 ' \mathrm{~W}\right)$}

$\begin{array}{lccccccc}\text { PS71-113-2-24 } & 10 & 3.06 & 0.80 & 0.06 & 83 & 92 & 35.4 \\ \text { PS71-113-2-22 } & 74 & 2.59 & 0.47 & 0.03 & 72 & 111 & 35.6 \\ \text { PS71-113-2-19 } & 101 & 2.69 & 0.54 & 0.04 & 76 & 108 & 35.8 \\ \text { PS71-113-2-14 } & 298 & 6.25 & 0.39 & 0.03 & 68 & 95 & 83.5 \\ \text { PS71-113-2-12 } & 401 & 6.56 & 0.48 & 0.04 & 51 & 93 & 87.8 \\ \text { PS71-113-2-10 } & 500 & 6.27 & 0.40 & 0.04 & 51 & 95 & 90.8 \\ \text { PS71-113-2-7 } & 1000 & 6.30 & 0.70 & 0.05 & 49 & 95 & 103 \\ \text { PS71-113-2-5 } & 1501 & 7.07 & 0.58 & 0.04 & 55 & 92 & 115 \\ \text { PS71-113-2-3 } & 1997 & 6.82 & 0.50 & 0.03 & 52 & 93 & 123 \\ \text { PS71-113-2-1 } & 2351 & 6.84 & 0.43 & 0.06 & 49 & 93 & 128\end{array}$

\section{Station PS71-163-1 $\left(67^{\circ} \mathrm{S}, 0^{\circ} \mathrm{E}\right)$}

\begin{tabular}{lccccccc} 
PS71-163-1-24 & 9 & 2.57 & 0.67 & 0.04 & 34 & 94 & 62.6 \\
PS71-163-1-22 & 45 & 4.42 & 0.27 & 0.05 & 203 & 86 & 64.8 \\
PS71-163-1-20 & 74 & 7.03 & 0.53 & 0.03 & 99 & 89 & 89.8 \\
PS71-163-1-18 & 171 & 7.08 & 0.49 & 0.03 & 98 & 85 & 95.6 \\
PS71-163-1-16 & 250 & 7.18 & 0.44 & 0.03 & 99 & 86 & 98.6 \\
PS71-163-1-14 & 401 & 7.14 & 0.57 & 0.03 & 98 & 92 & 104 \\
PS71-163-1-13 & 748 & 7.56 & 0.53 & 0.03 & 99 & 91 & 113 \\
PS71-163-1-11 & 1001 & 7.73 & 0.64 & 0.03 & 91 & 88 & 118 \\
PS71-163-1-9 & 1501 & 7.79 & 0.55 & 0.03 & 90 & 90 & 123 \\
PS71-163-1-7 & 2000 & 7.62 & 0.59 & 0.03 & 104 & 78 & 124 \\
PS71-163-1-5 & 3000 & 7.60 & 0.55 & 0.02 & 104 & 86 & 123 \\
PS71-163-1-3 & 4002 & 7.30 & 0.53 & 0.02 & 98 & 86 & 124 \\
PS71-163-1-1 & 4601 & 7.35 & 0.96 & 0.04 & 78 & 92 & 129 \\
\hline \\
Internal uncertainty, with all measurement uncertainties propagated through the double spike reduction \\
rocedure. Long-term standard reproducibility is greater at 0.08\%o (see text). \\
Total Zn analyses as obtained from the isotope dilution analysis. Total procedural blanks were 2-3 ng and the \\
Si data here and in Table 3 from Middag et al. (2011a).
\end{tabular}

$1077{ }^{1}$ Internal uncertainty, with all measurement uncertainties propagated through the double spike reduction 
1082 Table 3: $\mathrm{Zn}$ concentration $(\mathrm{nmol} / \mathrm{kg})$ and $\delta^{66} \mathrm{Zn}$ for 11 surface $(2-5 \mathrm{~m}$ depth) transect stations 1083 in the Atlantic sector of the Southern Ocean.

\begin{tabular}{|c|c|c|c|c|c|c|c|c|}
\hline IPY ID & $\begin{array}{c}\text { Longitude } \\
\left({ }^{\circ} \mathrm{E}\right)\end{array}$ & $\begin{array}{c}\text { Latitude } \\
\left({ }^{\circ} \mathrm{S}\right)\end{array}$ & $\begin{array}{c}{[\mathrm{Zn}]} \\
(\mathrm{nmol} / \mathrm{kg})\end{array}$ & $\begin{array}{c}\delta^{66} \mathrm{Zn} \\
(\%)\end{array}$ & 2 sigma $^{1}$ & $\begin{array}{c}\text { Total } \mathrm{Zn}^{2} \\
(\mathrm{ng})\end{array}$ & $\begin{array}{c}\text { Yield } \\
(\%)\end{array}$ & $\begin{array}{c}{[\mathrm{Si}]} \\
(\mu \mathrm{mol} / \mathrm{kg})\end{array}$ \\
\hline PS71-105 & 3.82 & 48.04 & 0.63 & 0.14 & 0.06 & 88 & 75 & 1.89 \\
\hline PS71-105 & 3.82 & 48.04 & 0.65 & 0.07 & 0.04 & 42 & 99 & \\
\hline PS71-105 & 3.82 & 48.04 & 0.65 & 0.11 & 0.03 & 41 & 98 & \\
\hline PS71-109 & 0.00 & 51.67 & 1.27 & 0.60 & 0.04 & 85 & 90 & 15.7 \\
\hline PS71-111 & -0.54 & 52.17 & 6.44 & 0.48 & 0.05 & 219 & 93 & 23.3 \\
\hline PS71-111 & -0.54 & 52.17 & 6.55 & 0.46 & 0.04 & 86 & 101 & \\
\hline PS71-111 & -0.54 & 52.17 & 6.53 & 0.42 & 0.03 & 106 & 97 & \\
\hline PS71-111 & -0.54 & 52.17 & 6.32 & 0.49 & 0.03 & 82 & 90 & \\
\hline PS71-111 & -0.54 & 52.17 & 6.55 & 0.45 & 0.04 & 88 & 89 & \\
\hline PS71-114 & 0.00 & 53.18 & 2.69 & 0.45 & 0.04 & 90 & 95 & 34.3 \\
\hline PS71-117 & 0.02 & 54.32 & 2.76 & 0.58 & 0.04 & 96 & 92 & 44.3 \\
\hline PS71-120 & 0.00 & 55.24 & 2.81 & 0.58 & 0.03 & 95 & 98 & 50.3 \\
\hline PS71-123 & 0.00 & 56.30 & 3.25 & 0.50 & 0.03 & 88 & 106 & 63.8 \\
\hline PS71-126 & 0.00 & 57.21 & 3.47 & 0.51 & 0.04 & 96 & 93 & 64.8 \\
\hline PS71-129 & 0.00 & 58.20 & 3.69 & 0.50 & 0.04 & 102 & 96 & 67.1 \\
\hline PS71-133 & 0.00 & 59.00 & 3.02 & 0.45 & 0.03 & 84 & 102 & 62.7 \\
\hline PS71-136 & 0.00 & 60.24 & 2.72 & 0.52 & 0.04 & 76 & 105 & 62.1 \\
\hline PS71-139 & 0.00 & 61.15 & 2.26 & 0.50 & 0.04 & 62 & 101 & 57.6 \\
\hline
\end{tabular}

${ }^{1}$ Internal uncertainty, with all measurement uncertainties propagated through the double spike reduction procedure. Long-term standard reproducibility is greater at $0.08 \%$ (see text).

${ }^{2}$ Total $\mathrm{Zn}$ analyses as obtained from the isotope dilution analysis. Total procedural blanks were 2-3 ng and the reported concentrations (in $\mathrm{nmol} / \mathrm{kg}$ ) are corrected for this blank.

${ }^{3} \mathrm{Zn}$ concentrations for sample PS111 reproduce across duplicate analyses of separate aliquots from the same 20 litre MPI container, but the data are highly anomalous. We suspect that the original 20 litre MPI bottle must have been contaminated before or during original sampling, and these data are not considered further. 
1095

1096

1097

1098

1099

1100

1101

1102

1103

1104

1105

1106

1107

1108

1109

1110

1111

1112

1113

1114

1115

1116

1117

\section{Figure Captions}

Fig. 1: A portion of the IPY ANT-XXIV/3 cruise track with sampling stations, positions of the Antarctic fronts and oceanographic regimes (see Orsi et al., 1995). AAZ = Antarctic Zone, $\mathrm{PFZ}=$ Polar Frontal Zone, SAZ $=$ Subantarctic Zone, $\mathrm{WG}=$ Weddell Gyre, ACC $=$ Antarctic Circumpolar Current, STF $=$ Subtropical Front, SAF $=$ Subantarctic Front, APF $=$ Antarctic Polar Front, SB-ACC $=$ Southern Boundary of ACC. Grey arrows and associated labels show schematic surface flow directions. The Bristol lab received 3 depth profiles (see red boxes) and a subset of large surface samples (all surface samples collected are indicated by filled black circles). Asterisks mark stations sampled with ultraclean Titan frame (de Baar et al., 2008), which includes all three depth profiles analysed here for $\mathrm{Zn}$.

Fig. 2: N-S vertical section for dissolved silicate $(\mu \mathrm{mol} / \mathrm{kg})$ along the Greenwich Zero Meridian. The line at the top shows the major fronts (green) and oceanic regimes (black) discussed in the text. Abbreviations are as in Figure 1. The depth profiles studied for $\mathrm{Zn}$ isotopes and concentrations are marked in white. Silicate data plotted using the ODV software (Schlitzer, 2002).

Fig. 3: Isotopic data for pre-co-precipitated seawater supernatant samples and MQ samples to which Zn JMC standard has been added. "Seawater 30 ng", "Seawater 200 ng" represent the supernatant samples to which $30 \mathrm{ng}$ and $200 \mathrm{ng}$ standard $\mathrm{Zn}$ were added respectively. The result obtained for the supernatant samples was $\delta^{66} \mathrm{Zn}=+0.08 \pm 0.03 \%$ o $(n=12)$. The slightly elevated $\delta^{66} \mathrm{Zn}$ suggests that a small amount of $\mathrm{Zn}$ was left in these samples after coprecipitation. The result for MQ samples was $\delta^{66} \mathrm{Zn}=-0.01 \pm 0.02 \%$ o $(\mathrm{n}=8)$, all falling within the error of the expected $0 \%$, demonstrating the robustness of the double spike approach.

Fig. 4: Plot of measured $\mathrm{Zn}$ isotopic data for $4 \mathrm{~L}$ surface Equatorial Atlantic samples to which various amounts of JMC standard and double spike have been added, versus the reciprocal $\mathrm{Zn}$ 
1120 amounts. In this case the original sample $\mathrm{Zn}$ was not removed, previous isotope dilution 1121 analysis having indicated that sample $\mathrm{Zn}$ concentrations were very small, at 0.01-0.04 nmol $1122 \mathrm{~kg}^{-1}$.

1123 Fig. 5: Plot of measured $\mathrm{Zn}$ concentration data for Station PS71-113-2 (red squares) 1124 compared with data for the same location in Croot et al. (2011) (green triangles) and with data 1125 for a composite of nearby stations $(895,897,947,949)$ published in Löscher (1999). The 1126 latter data are plotted as blue diamonds, with obvious outliers in this older dataset highlighted 1127 by the open symbols. Beneath $1000 \mathrm{~m}$ the data obtained here are in very good agreement with 1128 Löscher (1999) while the data of Croot et al. (2011) are displaced towards lower values.

1129 Fig. 6: Depth profiles of potential temperature $\left({ }^{\circ} \mathrm{C}\right)$, salinity, oxygen concentration $(\mu \mathrm{mol} / \mathrm{kg})$, 1130 silicon $(\mu \mathrm{mol} / \mathrm{kg})$, dissolved $\mathrm{Zn}$ concentration (nmol/kg), Zn isotopic composition (\%o) of 1131 samples collected at station PS71-163-1 (67' $\left.\mathbf{S}, \mathbf{0}^{\circ} \mathbf{E}\right)$. Salinities are reported on the Practical 1132 Salinity Scale (PSS78). Water mass abbreviations: AASW = Antarctic Surface Water; CIW = 1133 Central Intermediate Water; WSDW = Weddell Sea Deep Water; WSBW = Weddell Sea 1134 Bottom Water.

1135 Fig. 7: Depth profiles of potential temperature $\left({ }^{\circ} \mathrm{C}\right)$, salinity, oxygen concentration $(\mu \mathrm{mol} / \mathrm{kg})$, 1136 silicon $(\mu \mathrm{mol} / \mathrm{kg})$, dissolved $\mathrm{Zn}$ concentration (nmol/kg), $\mathrm{Zn}$ isotopic composition (\%o) of 1137 samples collected at station PS71-113-2 $\left(\mathbf{5 2}^{\circ} \mathbf{5 9 . 8 2 8}^{\prime} \mathbf{S}, \mathbf{0 . 2}^{\circ} \mathbf{0 . 0 5} \mathbf{W}\right)$. Water mass 1138 abbreviations as in Figure 6 plus: AAIW = Antarctic Intermediate Water; UCDW $=$ Upper 1139 Circumpolar Deep Water; LCDW = Lower Circumpolar Deep Water; WSBW = Weddell Sea 1140 Bottom Water.

1141 Fig. 8: Depth profiles of potential temperature $\left({ }^{\circ} \mathrm{C}\right)$, salinity, oxygen concentration $(\mu \mathrm{mol} / \mathrm{kg})$, 1142 silicon $(\mu \mathrm{mol} / \mathrm{kg})$, dissolved $\mathrm{Zn}$ concentration $(\mathrm{nmol} / \mathrm{kg}), \mathrm{Zn}$ isotopic composition (\%o) of 
1143 samples collected at station PS71-104-2 (47 $\left.{ }^{\circ} 39.36 ' \mathbf{S}, 4^{\circ} \mathbf{1 5 . 7}^{\prime} \mathbf{E}\right)$. Water mass abbreviations as

1144 in Figure 6,7 plus: NADW = North Atlantic Deep Water.

1145 Fig. 9: Plots of measured salinity, Si concentration $(\mu \mathrm{mol} / \mathrm{kg})$, dissolved $\mathrm{Zn}$ concentration 1146 (nmol/kg), Zn isotopic composition $\delta^{66} \mathrm{Zn}(\%)$ of surface transect samples (filled diamonds) 1147 and near surface samples (open diamonds) collected at vertical profiles PS71-104-2, PS711148 113-2, PS71-163-1 against latitude. Abbreviations for surface oceanographic regimes as in 1149 Fig. 1.

1150 Fig. 10: Cross-plots of Si concentrations versus (a) the new Zn concentration and (b) isotopic 1151 data. Data from the ACC (north of $56^{\circ} \mathrm{S}$ ) are plotted as red squares and data from the Weddell 1152 Gyre (WG, south of $56^{\circ} \mathrm{S}$ ) as blue circles. Solid symbols are for surface samples (collected at 1153 2-5m and presented in Table 3), and open symbols for sub-surface (from depths $\geq 10 \mathrm{~m}$, as 1154 presented in Table 2) and deep samples.

1155 Fig. 11: A summary of $\mathrm{Zn}$ isotopic data thus far available for different parts of the world's 1156 deep oceans $(\leq 1000 \mathrm{~m})$, compared to estimates of the likely inputs to the ocean (Little et al., 1157 2013). The solid vertical line shows the $\delta^{66} \mathrm{Zn}$ of rivers, the dashed line that for Atlantic 1158 aerosols, and the dot-dash line that for silicate rocks and sediments of the continental crust (all 1159 compiled in Little et al., 2013). Blue filled diamonds represent the deep North Atlantic 1160 (BATS; Boyle et al. 2012), red filled squares the deep North Pacific (SAFe; this study), and 1161 green filled triangles the deep Southern Ocean (Atlantic sector, this study, arranged by depth 1162 (green arrow), and omitting the bottom-most sample from Station PS71-163). Data plotted for 1163 Southern Ocean samples are single analyses and their associated analytical uncertainties $1164( \pm 0.08 \%$ ). Data for the Atlantic and Pacific are averages and 2SEs of multiple analyses of the 1165 same sample. The shaded green band shows 2SE either side of the mean for all the deep ocean 1166 data. 


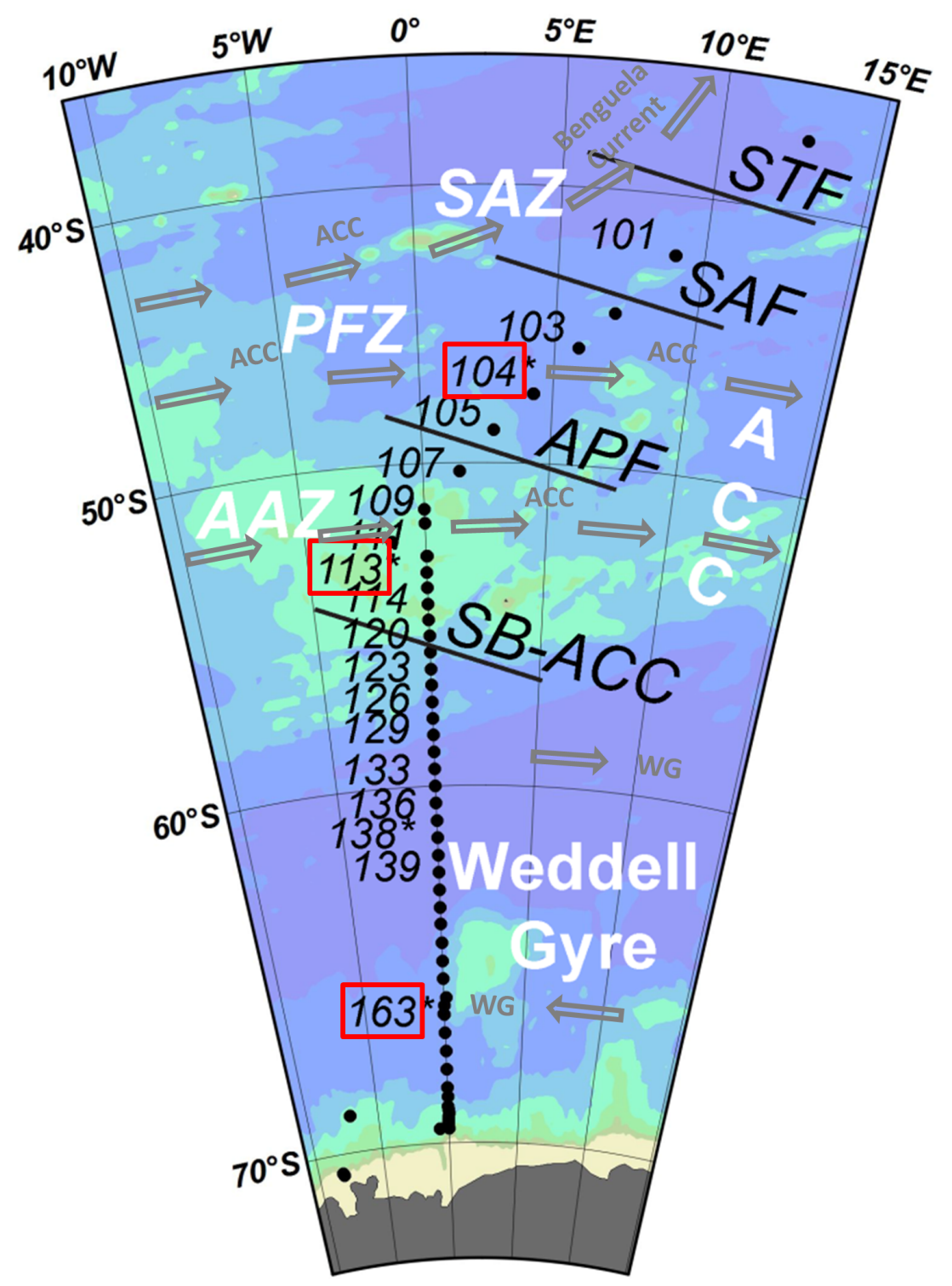

1169

1170

1171 


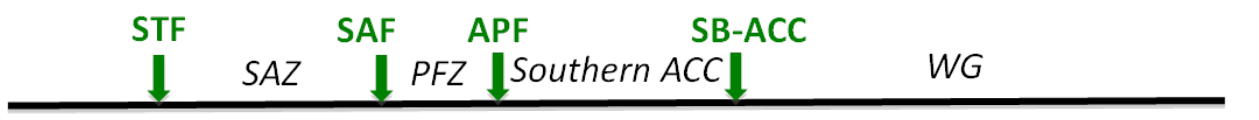

\section{Si [umol/kg]}

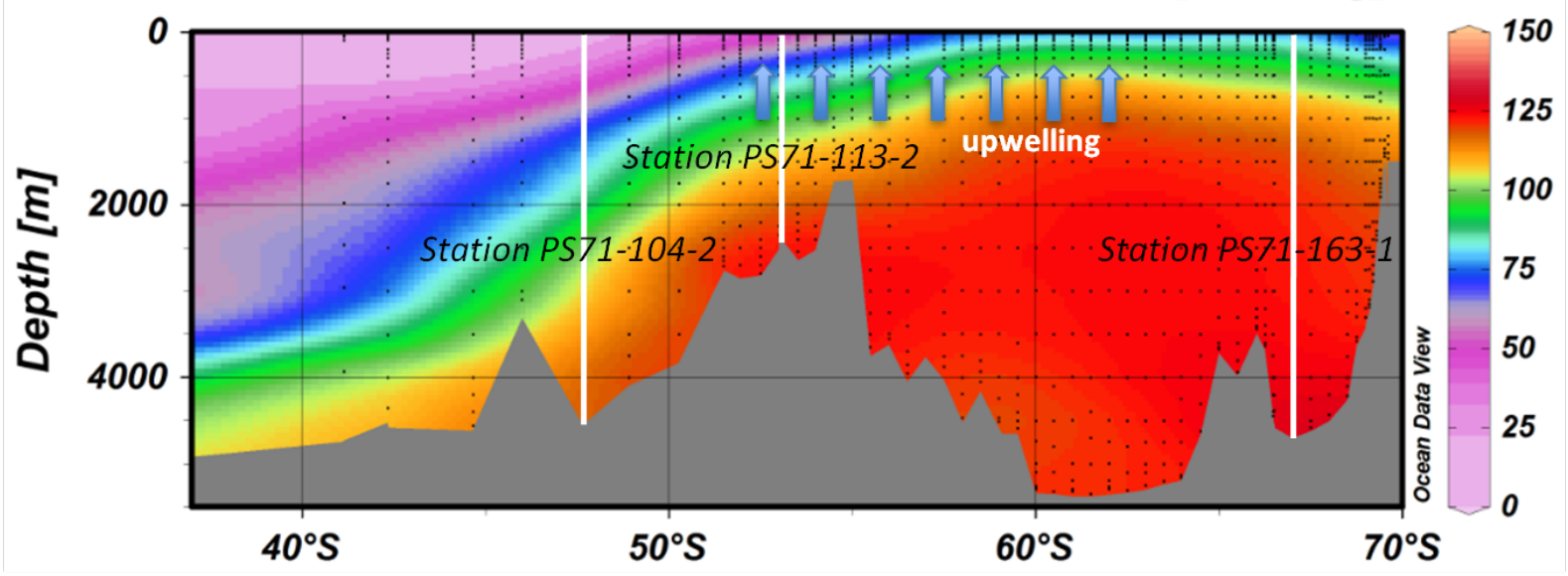

1174 
Zhao et al. - Figure 3

1177

1178
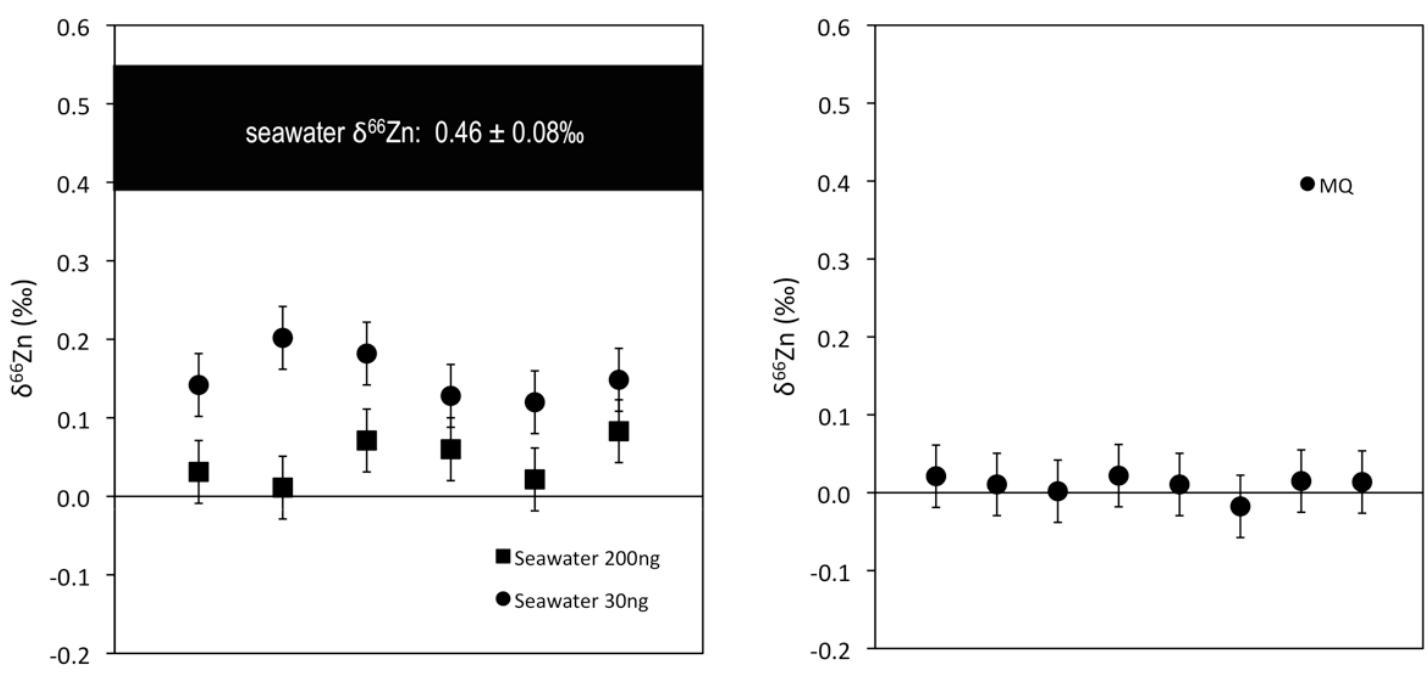

1179 
Zhao et al. - Figure 4

1181

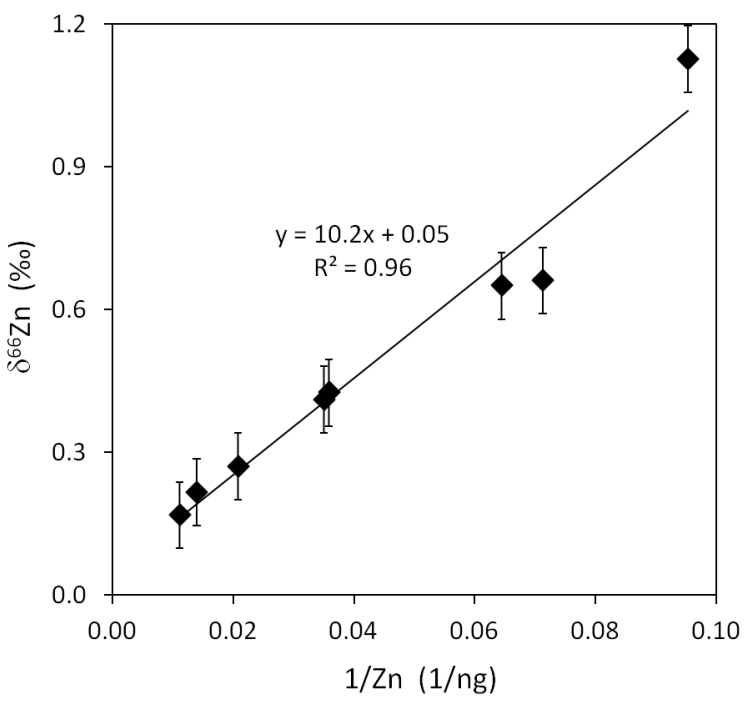

1182

1183

1184 
Zhao et al. - Figure 5

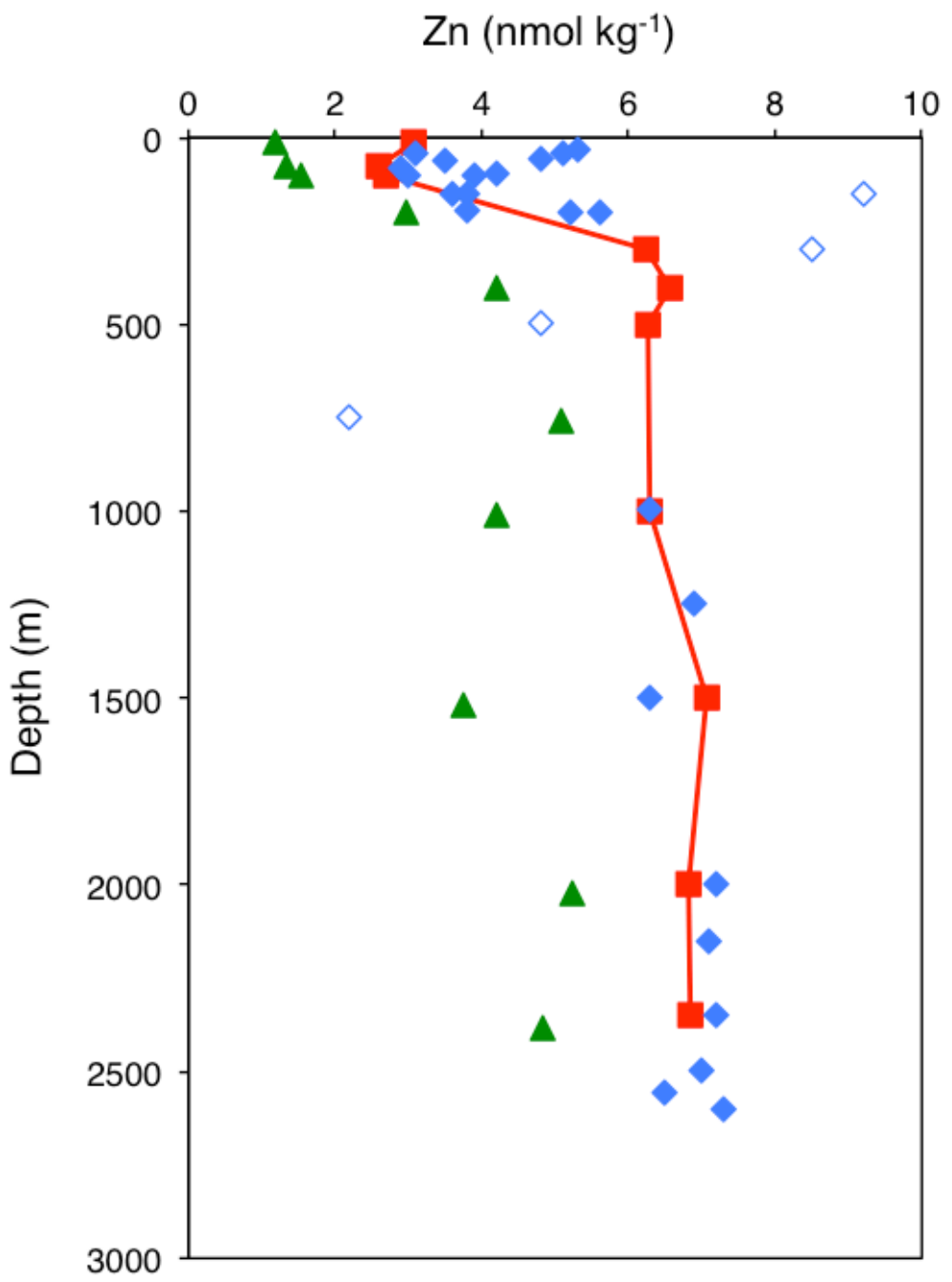

1186 
Zhao et al. - Figure 6

PS71-163-1
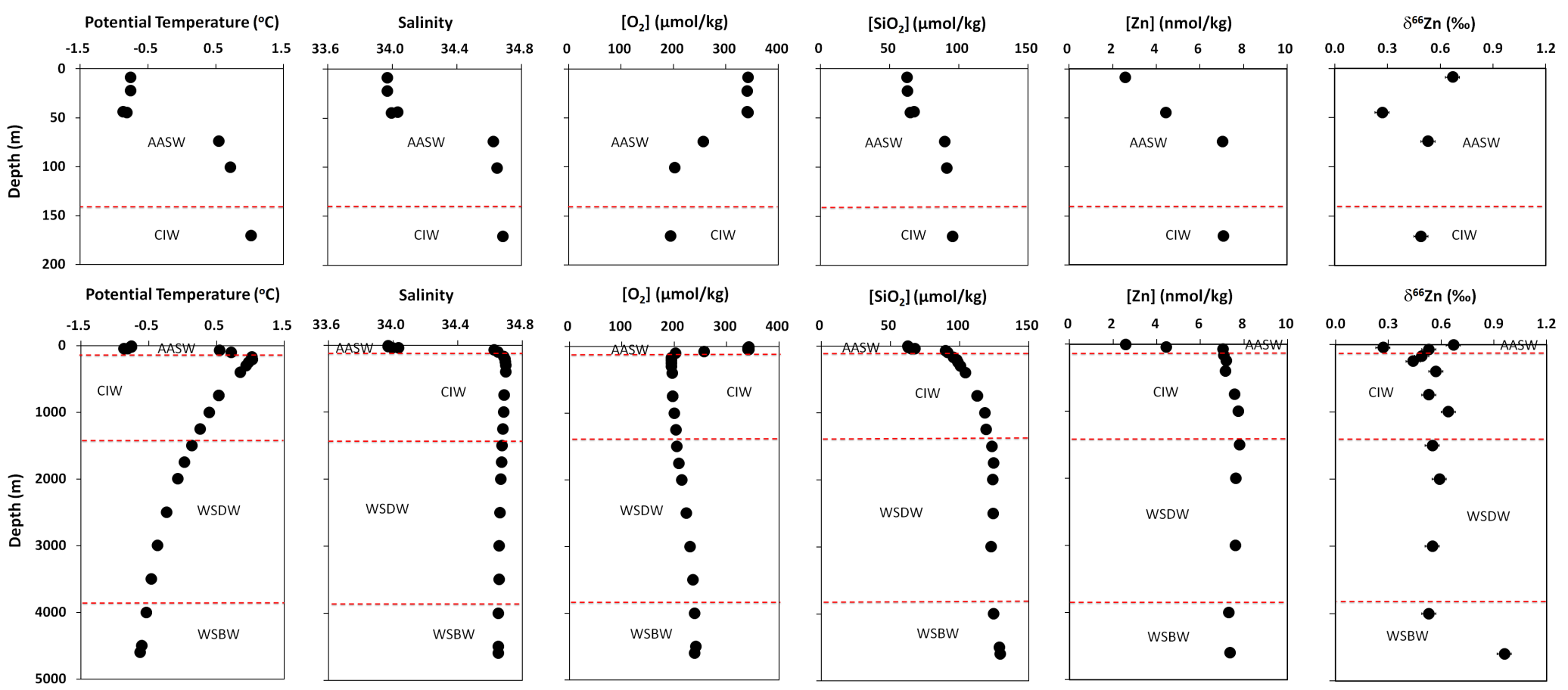
Zhao et al. - Figure 7

PS71-113-2
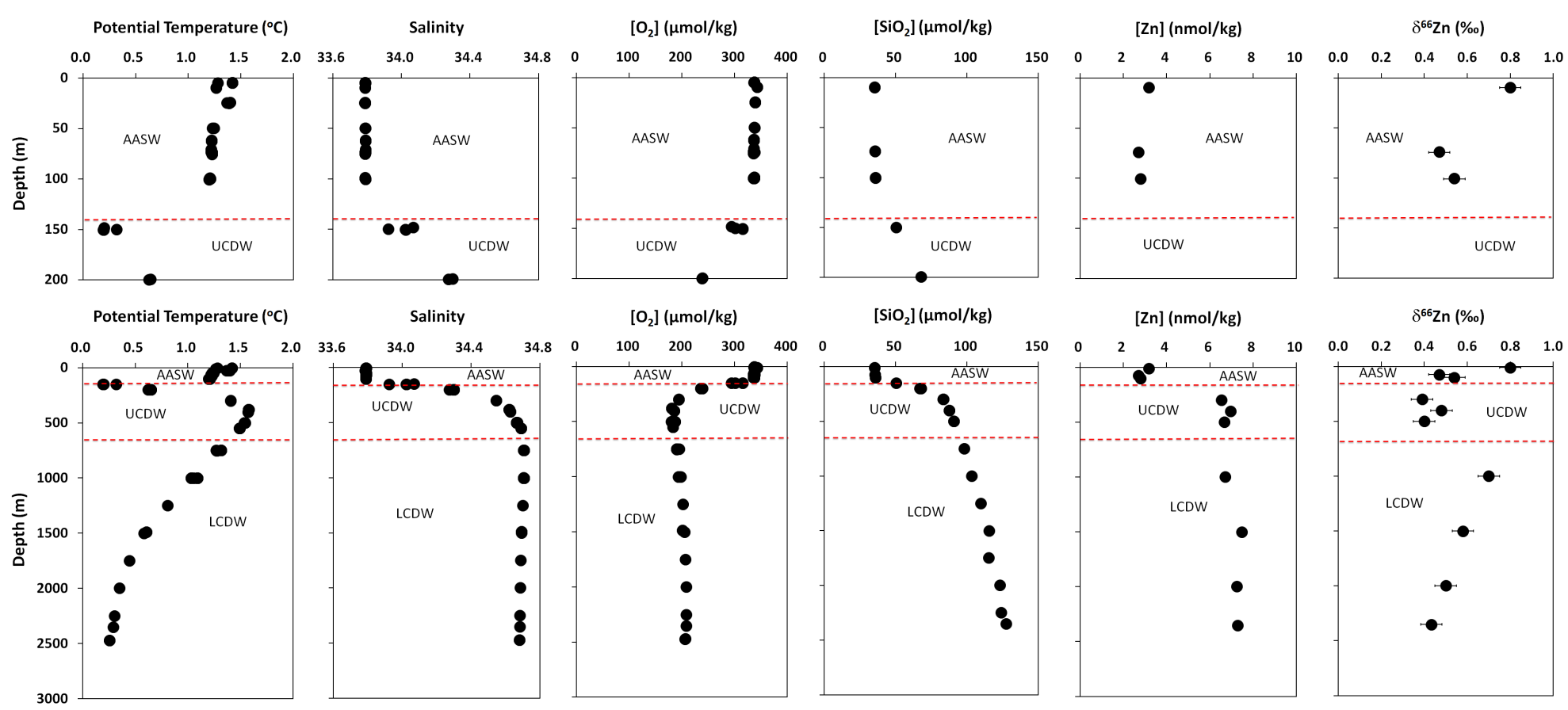
PS71-104-2
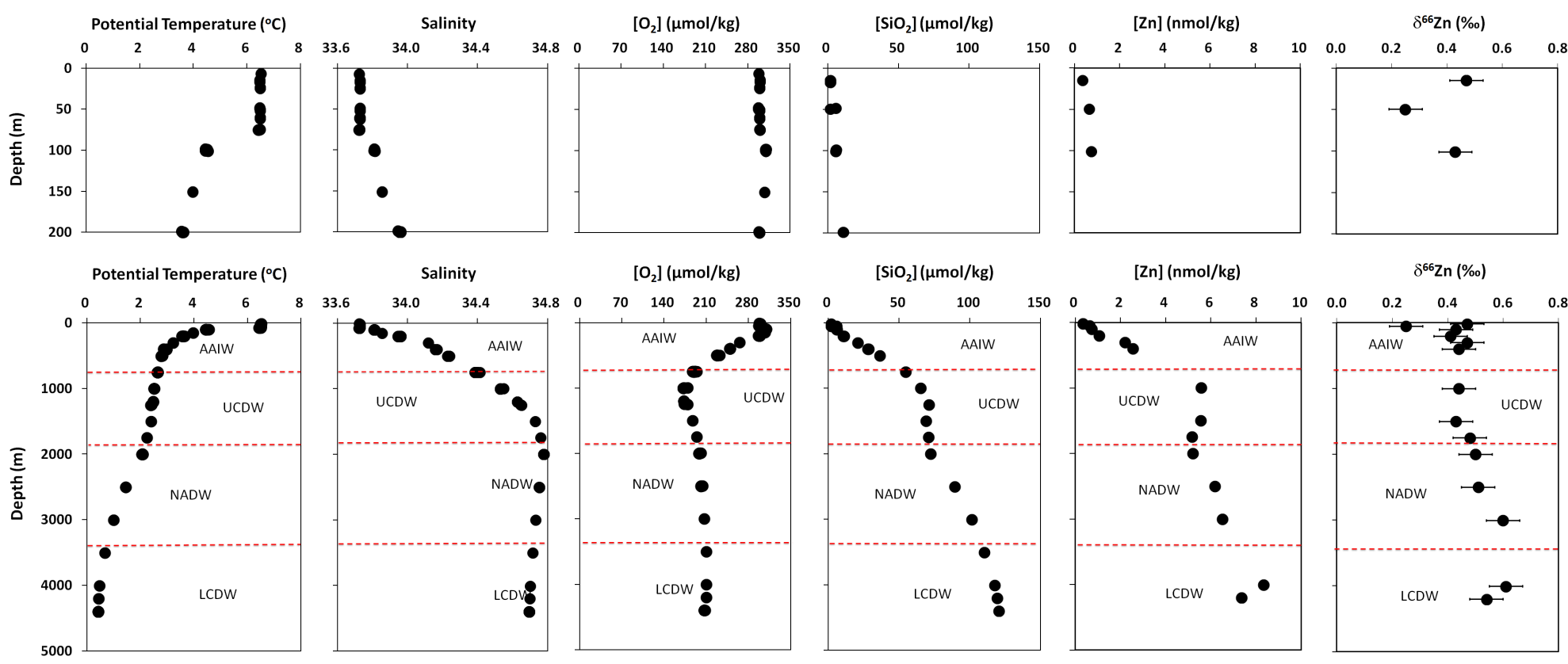

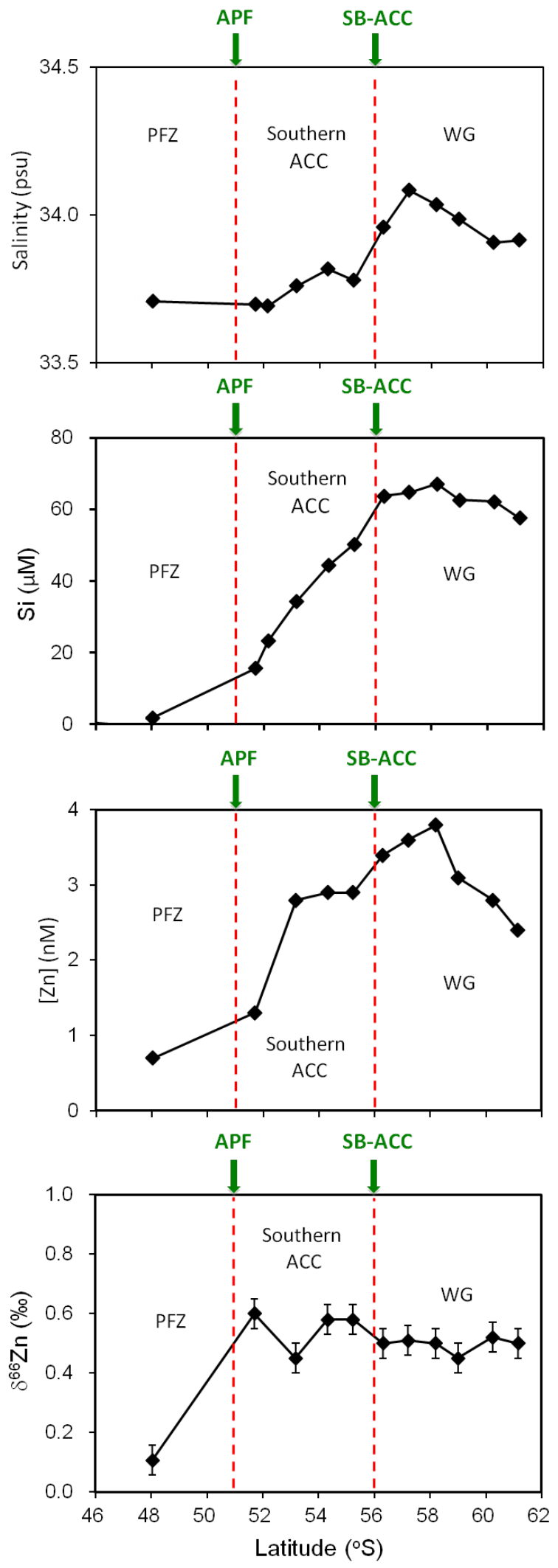
Zhao et al. - Figure 10
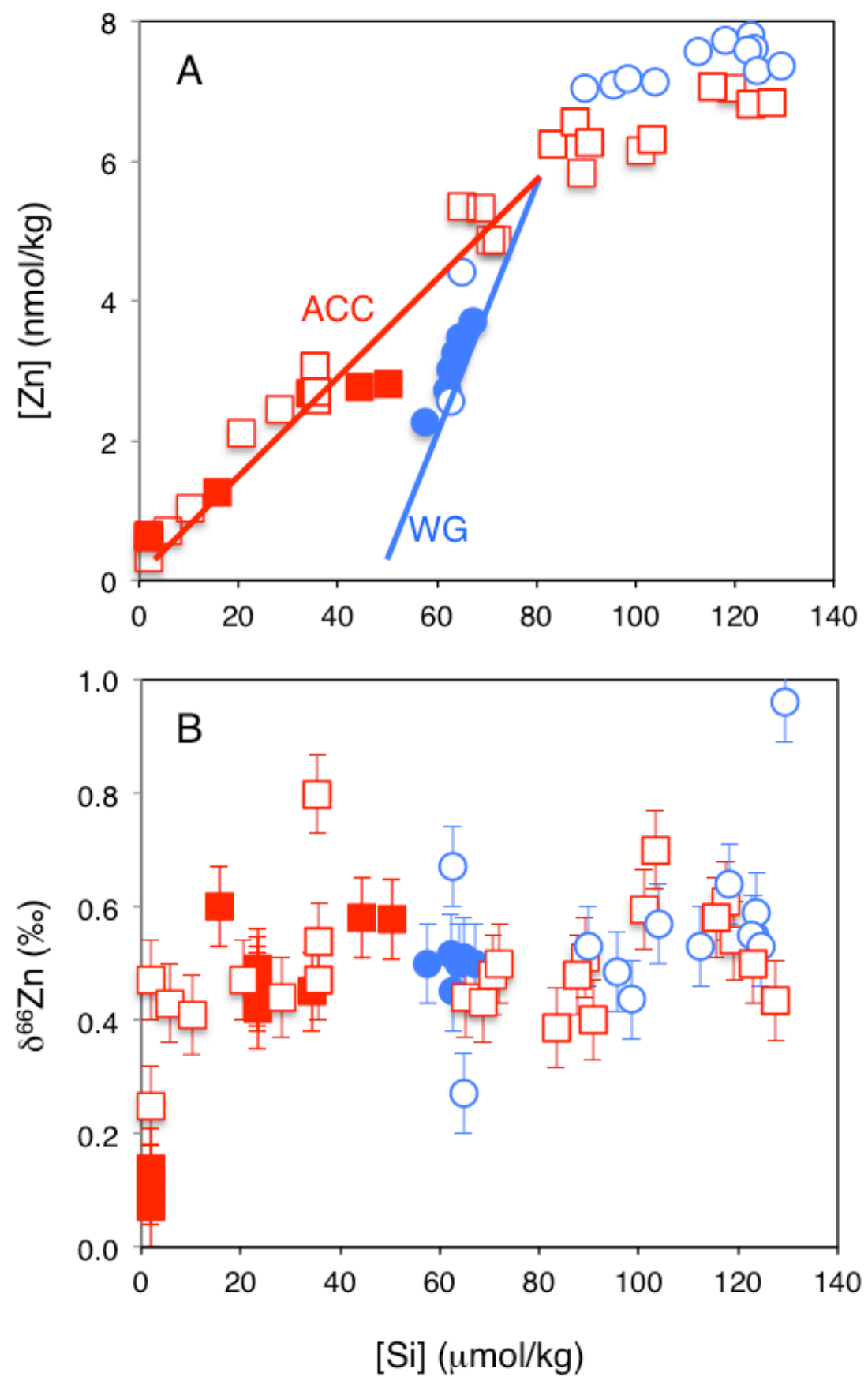

1200 
1201

1202

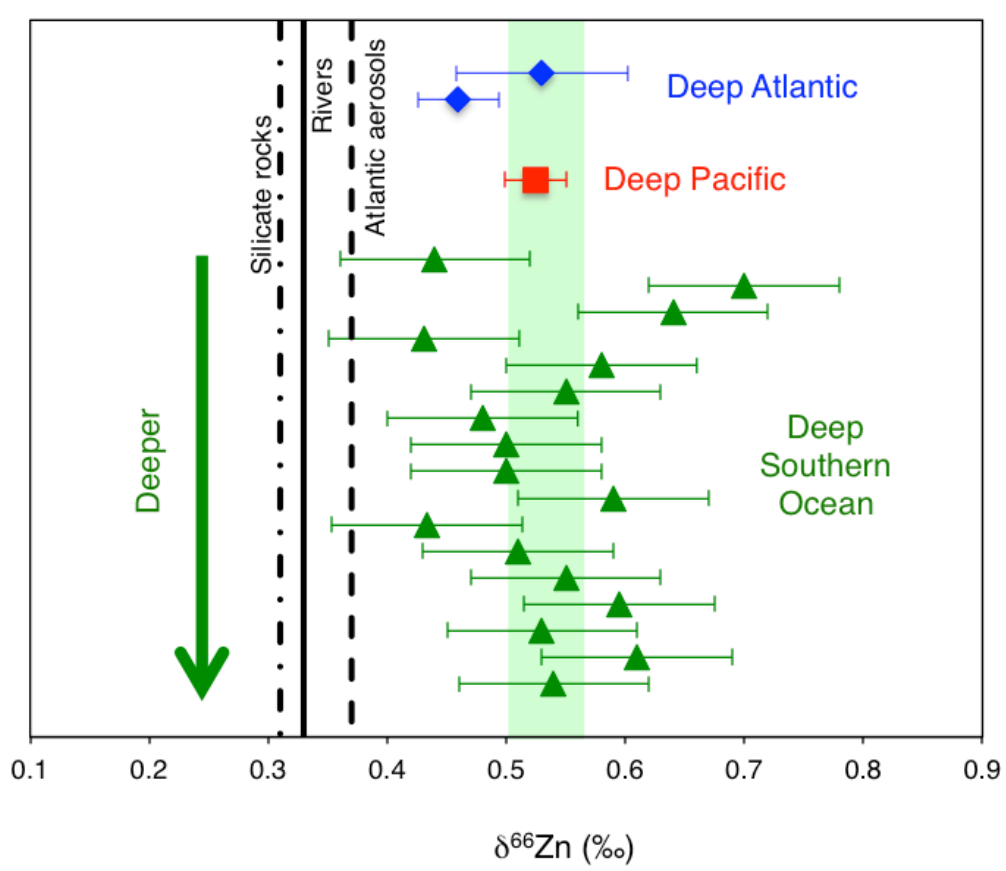

1203

Zhao et al. - Figure 11

120

1204

1205

1206 